Mixed Union Formation among 1.5 and Second-generation Immigrants in Denmark: The Role of Cultural Proximity and Opportunity Structures

Hans-Peter Y. Qvist*

Jeevitha Yogachandiran Qvist**

* Department of Sociology and Social Work, Aalborg University, Denmark. Direct correspondence to hpq@socsci.aau.dk

** Department of Politics and Society, Aalborg University, Denmark

This version is a preprint (January 27, 2022)

\title{
Acknowledgements
}

For helpful comments and feedback on this piece, we thank Dingeman Wiertz, Christian Albrekt Larsen, Jeppe Fjeldgaard Larsen, Lanciné E. N. Diop, Anna Diop-Christensen, and Rasmus Munksgaard. This work was supported by the Independent Research Fund Denmark (grant number: 9130-00004B). 


\begin{abstract}
Immigrants' likelihood of mixed union formation differs depending on their country of origin for unclear reasons. Cultural proximity theory suggests that immigrants' likelihood of mixed union formation depends on the cultural proximity between their country of origin and the receiving country. Opportunity structure theory, on the other hand, suggests that immigrants' likelihood of mixed union formation depends on their opportunities to find suitable partners from their own national origin group in local partner markets in the destination country. This study uses administrative register data to examine union formation patterns among 1.5 and second-generation immigrants in Denmark. We follow 71,122 1.5 and second-generation immigrants from 120 different national origin groups residing in 11 local partner markets in Denmark from age eighteen until they form their first union or right censoring occurs. Our results using multilevel discrete-time event history analysis suggest that differences in the likelihood of mixed union formation are explained partly by cultural factors, such as religion, language, and degree of globalization, and partly by the opportunity structures in local partner markets, such as group size, sex ratio, and within-group educational similarity. However, cultural proximity explains a much larger proportion of the variation in mixed union formation between national origin groups than opportunity structures do.
\end{abstract}


In the last 30-40 years, there has been rapid immigration from non-Western countries to Western countries. In Europe (Pettigrew 1998b) and the United States (Rumbaut 2001), this development has led to lively academic and public debate about the extent to which these immigrants, and in particular their descendants, will become incorporated into the culture and structure of societies (Drouhot and Nee 2019).

Historical evidence suggests that the extent to which members of an immigrant group intermarried with natives was closely linked to the group's wider cultural and structural incorporation into the destination society. Early studies thus suggest that intermarriages between European immigrants and native-born Americans marked and accelerated European immigrants' incorporation into American society during rapid immigration from European countries to the United States in the late 19th and early 20th centuries (Alba and Nee 1997; Gordon 1964; Warner and Srole 1945).

Unlike classical studies that considered only legal marriages (Gordon 1964; Warner and Srole 1945), our focus is on union formation, referring to both nonmarital cohabitation and legal marriage. We focus on union formation because nonmarital cohabitation—or living together in a marriage-like relationship - for many couples during the last decades has shifted status from a temporary phase that occurs before they enter into matrimony to a permanent living arrangement (Sassler and Lichter 2020).

There are several reasons why mixed union formation marks and accelerates immigrants' incorporation into a receiving society. First, the formation of mixed unions indicates that ethnic group boundaries are not strong enough to prevent the formation of intimate and trusting relationships between two people of different ethnic groups (Lichter, Qian, and Tumin 2015). Second, a mixed union usually unites couples' family, friends, and relatives across ethnic groups 
(Van Leeuwen et al. 2019). This ensures that members of society have extensive nonsuperficial contact across groups, which is believed to reduce interethnic prejudice and conflict (Allport 1954; Pettigrew 1998a), to increase interethnic social trust (Putnam 2007), and ultimately to strengthen the social cohesion of society. Third, evidence suggests that immigrants who form mixed unions with natives are more strongly connected to the labor market and enjoy higher earnings, suggesting that the formation of mixed unions, especially with natives, may aid immigrants' socioeconomic incorporation into society (Elwert and Tegunimataka 2016). Fourth, the offspring of mixed unions contribute to a blurring of ethnic group boundaries because they are less likely to strongly identify with one particular ethnic group and because it is difficult for other people to determine their ethnicity (Alba, Beck, and Sahin 2018). Fifth, and finally, a high rate of mixed unions within an immigrant group may be self-reinforcing because it generally signals that ethnic and cultural boundaries are permeable and thereby may inspire others to form relationships across ethnic divides (Harris and Ono 2005).

In the United States in the late $19^{\text {th }}$ and early $20^{\text {th }}$ centuries, European immigrants, in general, became more likely to form mixed unions with Americans over their life cycles and successive generations (Gans 1992; Warner and Srole 1945). However, in contemporary Europe (Kulu and Gonzalez-Ferrer, 2014; Lanzieri 2012) and the United States (Alba and Nee, 2003), it is evident that immigrants' likelihood of mixed union formation differs depending on their country of origin for unclear reasons. Cultural proximity theory suggests that immigrants' likelihood of mixed union formation depends on the cultural proximity between their country of origin and the receiving country. Opportunity structure theory, on the other hand, suggests that immigrants' likelihood of mixed union formation depends on their opportunities to find suitable partners from their own national origin group in local partner markets in the destination country. 
To disentangle cultural proximity and opportunity structure theory, studies from Great Britain (Muttarak and Heath 2010) and the United States (Kalmijn and Van Tubergen 2010; Spörlein et al. 2014) have used multilevel models that separate contextual, group-level, and individual-level effects. Overall, the studies found evidence that immigrants' union formation patterns were shaped by both cultural characteristics of their countries of origin and opportunity structures in local partner markets; this was also the case when individual-level factors were controlled for (Kalmijn and Van Tubergen 2010; Muttarak and Heath, 2010; Spörlein et al. 2014). However, Kalmijn and van Tubergen (2010) went a step further and disentangled the relative importance of cultural characteristics of immigrants' countries of origin and opportunity structures measured in local partner markets. Based on a cross-sectional multilevel analysis of 93,777 1.5 and second-generation immigrants from 94 different national origin groups in the United States, Kalmijn and van Tubergen (2010) concluded that cultural characteristics of the immigrants' countries of origin, including religion, language, and degree of globalization, explained a much larger proportion of the group-level variance in the likelihood of intermarriages than indicators for opportunity structures did.

The aim of this study is to examine whether Kalmijn and van Tubergen's (2010) conclusion is corroborated if we extend their multilevel approach to a longitudinal setting and use it to study 1.5 and second-generation immigrants' union formation patterns in Denmark. Here, 1.5 generation immigrants refers to those who immigrated before age 18 and second-generation immigrants refers to native-born persons of foreign parentage (Rumbaut, 2012). There are two main benefits of a longitudinal approach in which the same 1.5 and second-generation immigrants are followed over time from when they become adults until they possibly form a union. These benefits have already been highlighted in previous longitudinal research (Dribe and Lundh, 2011; Kulu and Hannemann, 2019) but have so far not been explored in combination with a multilevel approach. 
First, a longitudinal approach addresses the fact that the share of immigrants who remain single differs between national origin groups, resulting in right censoring. Second, a longitudinal approach addresses the fact that the characteristics of national origin groups change over time because of the influx of new immigrants and differences in fertility rates across groups. This is important because the opportunities for unmixed union formation will grow larger over time within national origin groups whose size grows at a faster rate than other groups. Moreover, at the individual level, immigrants' attractiveness in the partner market may change over time as a function of time-varying socioeconomic covariates.

\section{The Case of Denmark}

Denmark offers an interesting case for the study of immigrants' union formation patterns. Unlike traditional immigration countries, such as Australia, Canada, and the United States, or former colonial countries, such as Great Britain, Spain, and the Netherlands, Denmark was a very ethnically and culturally homogenous country until the 1960s (Togeby 1998). Denmark in fact experienced more emigration than immigration until the mid-twentieth century, and the majority of the immigrants who came to Denmark were from other European countries, mostly other Nordic countries (Nusche, Wurzburg, and Naughton 2010). This means that prior to the 1960s, no national origin groups from non-Western countries assumed a particularly disadvantaged position in Danish society because of historical legacies related to slavery or other legal segregation.

The influx of non-Western immigrants to Denmark began in the 1960s, when Denmark experienced close to full employment. Consequently, guest workers from Turkey, the former Yugoslavia, and Pakistan were welcomed during this period. However, while the influx of guest workers came to a sudden halt after the oil crisis struck in 1974, immigration to Denmark 
continued because many of the guest workers settled in Denmark and were granted family reunification. The influx of non-Western immigrants markedly increased in the mid-1980s in part because of family reunifications and in part because the number of refugees increased greatly from war-torn countries, such as Iran, Iraq, and Sri Lanka. In the 1990s and 2000s, the influx of immigrants and refugees continued, and they currently include greater numbers of immigrants from African countries, such as Somalia, and from Middle Eastern countries, such as Syria.

The fact that Denmark has a very recent history of immigration suggests that theories about the marital assimilation of immigrants and their descendants can be tested without being confounded by possibly path-dependent racial divides such as the one between African and white Americans in the United States. The reason for this is that evidence suggests that marital assimilation is much less dependent on race or skin color in European countries with no internal history of slavery or other legal segregation than in the United States (Lucassen and Laarman 2009).

\section{Theoretical Background}

A large body of studies from Europe and the United States has documented that immigrants' rates of mixed union formation differ depending on their country of origin (Alba and Nee, 2003; Kalmijn 1998; Kulu and Gonzalez-Ferrer, 2014; Lanzieri 2012). Cultural proximity and opportunity structure theory offer complementary explanations for this empirical regularity.

\section{Cultural Proximity Theory}

Cultural proximity theory suggests that immigrants' likelihood of mixed union formation depends on the cultural proximity between their country of origin and the receiving country. Here, the term 
'culture' is used broadly to encompass cultural factors that shape peoples' norms, values, and beliefs, including religion, language, and globalization (Triandis 1994). Cultural proximity theory recognizes the relational nature of the union formation process by focusing on the proximity or distance between two cultures rather than on specific cultural traits that make mixed union formation more or less likely.

The religious orientation of a national origin group is likely to affect its members' likelihood of mixed union formation both directly and indirectly. Directly because some religious communities discourage interreligious unions. Consequently, some 1.5 and second-generation immigrants may avoid nonsuperficial contact with the native population or other immigrant groups in the form of friendships, dating, clubbing, or get-togethers that could lead to romantic relationships because they fear social sanctions from other members of their religious communities. In particular, this is likely to apply to 1.5 and second-generation immigrants who belong to highly religious communities since the level of religiosity is inversely associated with the disapproval of interethnic romantic relationships (Carol 2013; Carol, Ersanilli, and Wagner 2014). The religious orientation of a national origin group may also affect its members' likelihood of mixed union formation indirectly since people who share the same religion are also more likely to share norms, values, practices, and beliefs that are associated with the religion. Moreover, religious denominations frequently function as key meeting places for people who share the same religion.

The dominant religion in Demark is Christianity, and although the constitution has ensured full freedom of religion since 1849, the Evangelical-Lutheran Folk Church remains supported by the state (Lodberg 2000). Following cultural proximity theory, we should therefore expect members of Christian national origin groups to be more likely to form mixed unions with the native population than members of national origin groups with other religious orientations. We further expect that female 1.5 and second-generation immigrants from Muslim national origin 
groups will be less likely to form mixed unions with natives than their male counterparts and more likely to form unmixed unions. This expectation is due to a number of reasons. First, while most Muslim communities in Western countries generally accept unions or marriages between Muslim men and Christian women, many discourage the opposite combination. Second, 1.5 and secondgeneration immigrants from Muslim national origin groups in Western countries appear to have stronger religious identities than immigrants and second-generation immigrants from other national origin groups. Moreover, their religious identities do not appear to fade over their life cycles or across generations (Voas and Fleischmann 2012). The reasons for this appear to be a mixture of cultural transmission from the country of origin and social inequality and closure in the destination country (Drouhot 2021). In contrast to the highly religious 1.5 and second-generation immigrants from Muslim countries, the native population in Denmark is characterized by low and decreasing levels of religiosity (Voas 2009), and church membership rates have declined rapidly over the last decades, albeit at a faster rate in urban than in rural areas of Denmark (Lund, Jørgensen, and Riis 2019). Third, as in most other countries in Europe, in Denmark, prejudice against Muslim 1.5 and second-generation immigrants is more prevalent and stronger than that against other 1.5 and second-generation immigrants (Strabac and Listhaug 2008). This suggests that natives may view 1.5 and second-generation immigrants from Muslim countries as less attractive partners than 1.5 and second-generation immigrants from other countries (Elwert 2020). Fourth, evidence from Denmark suggests that Muslim 1.5 and second-generation immigrants generally consider the religion of a potential partner highly important. In 2004, a small survey of 628 young immigrants and secondgeneration immigrants aged 17-27 from former Yugoslavia, Turkey, Pakistan, Lebanon, and Somalia revealed that more than half agreed to some or a large extent that it is important in a relationship that both parties share the same religion (Schmidt and Jakobsen 2004). 
Although our study population comprises only 1.5 and second-generation immigrants, who can generally be expected to speak Danish, we nevertheless expect that language might be a barrier to mixed union formation. The reason for this is that 1.5 and second-generation immigrants' families and friends may not speak Danish. We therefore expect 1.5 and second-generation immigrants from Norway, Sweden, and Iceland to be more likely to form mixed unions with natives than other national origin groups. The reason is that Swedish and Norwegian languages are so similar to Danish that people are able to understand each other. Moreover, Danish is a compulsory second language in Iceland.

The level of globalization of a country is likely to affect its people's lifestyle and their openness to other cultures (Kalmijn and Van Tubergen 2010). People from highly globalized countries are, for example, more likely to have traveled to other countries, to have consumed cultural products, such as food, books, and movies, from other countries and to be more accustomed to the mixing of cultures. On these grounds, we expect members of national origin groups whose countries of origin are more globalized to be more likely to form mixed unions either with the native population or with another immigrant than members of national origin groups whose countries are less globalized.

\section{Opportunity Structure Theory}

Opportunity structure theory suggests that immigrants' likelihood of mixed union formation depends on their opportunity to find a partner from their own national origin group who satisfies their preferences in their local partner market in their destination country (Kalmijn 1998). Opportunity structure theory was pioneered by Blau and colleagues, who found that the relative size of a national origin group was inversely related to its members' likelihood of mixed union 
formation with the native population in the United States (Blau 1977; Blau, Blum, and Schwartz 1982). On these grounds, Blau and colleagues theorized that this is because members of large national origin groups have a larger pool of potential within-group partners to choose from and because in-group norms that discourage mixed unions are more difficult to maintain in small groups than in large groups given that the alternative is singlehood. Later cross-sectional evidence from the United States and various European countries has supported the purported inverse relationship between relative group size and immigrants' likelihood of mixed union formation with the native population (Kalmijn and Van Tubergen 2010; Lichter, Carmalt, and Qian 2011; Muttarak and Heath 2010; Qian and Lichter 2007). Consequently, we expect that 1.5 and second-generation immigrants from larger national origin groups will be less likely to form mixed unions either with the native population or with another immigrant and more likely to form unmixed unions.

Other important opportunity structures that have been found to shape immigrants' and their descendants' likelihood of mixed union formation is within-group sex ratio and socioeconomic similarity. The reason that the within-group sex ratio may affect 1.5 and second-generation immigrants' union formation patterns is that the opportunities for finding a partner from one's own group are greater for female 1.5 and second-generation immigrants if the national origin group is dominated by men or vice versa. During the period of investigation, some national origin groups in Denmark had slightly male-dominated sex ratios. The reason for this is that more men than women usually manage to flee or migrate shortly after the onset of unrest, turmoil, or war in a particular country. Usually, however, the sex ratios become more balanced over time due to family reunifications. Nevertheless, we expect that women from national origin groups that are dominated by men will be less likely to form mixed unions either with the native population or with other immigrants and more likely to form unmixed unions. Within-group socioeconomic similarity may shape 1.5 and second-generation immigrants' opportunities for unmixed union formation because 
people usually find spouses who are similar to themselves in terms of socioeconomic indicators, such as education (Blossfeld 2009; Mare, 1991; Schwartz and Mare 2005). On these grounds, we expect that 1.5 and second-generation immigrants from national origin groups with a higher degree of within-group educational similarity are less likely to form mixed unions either with the native population or with other immigrants and more likely to form unmixed unions.

In recent decades, an important body of repeated cross-sectional studies has investigated to what extent members of national origin groups whose size, sex ratio, or educational diversity change over time become more or less likely to form mixed unions. Qian and Lichter (2007), for example, provided evidence that the arrival of new Asian and Hispanic immigrants during the period from 1990-2000 in the United States decreased the likelihood of mixed union formation between native-born Asian Americans and Hispanic Americans and white Americans because it expanded their opportunities for unmixed union formation (see also Lichter et al. 2011). Spörlein et al. (2014) also provided evidence, using an extraordinary dataset from the United States that covered the period from 1880-2011, that immigrants became more likely to marry outside of their own ethnic group if the size of their national origin group decreased, if its sex ratio grew more imbalanced, and if it became increasingly educationally diverse.

In Denmark, in the 1980-2018 period, the share of immigrants and second-generation immigrants in the population grew from 3 percent to 14 percent (DST 2018). Moreover, some national origin groups grew much faster than others, suggesting that the opportunity structures that shape 1.5 and second-generation immigrants' opportunities for unmixed union formation changed over time. In the 1988-2018 period, the number of immigrants from Western countries - referring to immigrants from EU countries and Iceland, Norway, Andorra, Liechtenstein, Monaco, San Marino, Switzerland, the Vatican State, Canada, USA, Australia and New Zealand - doubled. However, non-Western immigrants - referring to all other immigrants - increased more than fourfold (DST 
2018). Moreover, in the 1988-2018 period, the number of second-generation immigrants from Western countries increased threefold, while the number of second-generation immigrants from non-Western countries increased eightfold (DST 2018). Figures 1 and 2 show the relative size per thousand of the ten largest national origin groups from Western and non-Western national origin groups in Denmark, respectively.

[Figure 1]

Figure 1. The Relative Size of the Ten Largest National Origin Groups from Western Countries in Denmark

[Figure 2]

Figure 2. The Relative Size of the Ten Largest National Origin Groups from Non-Western Countries in Denmark

How to Delimit Partner Markets?

Many studies on the role of opportunity structures in shaping union formation patterns have measured opportunity structures at the national level and thereby assumed that a single national partner market exists. However, in recent years, it has frequently been argued that opportunity structures are better measured within smaller geographical units (Harris and Ono 2005). In this study, we measured the opportunity structures (i.e., group size, within-group sex ratio, and withingroup educational similarities) in local partner markets defined by 11 provinces in Denmark (for details about the provinces, see the variables section).

\section{Data, Measures, and Analytical Strategy}


For our study, we used data from different administrative registers maintained by Statistics Denmark. It is possible to merge information from different administrative registers because the Danish Civil Registration System requires all people who take residence in Denmark to hold a unique personal identification number that is available anonymized to approved researchers through protected servers at Statistics Denmark. The data included all registered marriages and cohabiting unions in the 1986-2016 period. Cohabiting unions were defined as two persons living at the same address with a common child or as two people of different sexes whose age difference was less than fifteen years who shared the same address without being related to each other by kinship. Because we use a proxy to capture union formation without a common child, we may in rare cases where two people of different sexes of the same age share the same address without being related by kinship wrongly classify roomies as cohabiting unions. However, in light of the rise of cohabitation, we considered this possible misclassification of roomies a smaller problem than excluding cohabiting unions without common children. There are two main reasons why we consider it crucial to include all cohabiting unions, including those without common children. First, if members of some national origin groups are more likely to marry or have children later in life than others, excluding cohabiting unions without common children could lead to misleading results. Second, time-varying opportunity structures, for example, relative group size, are theorized to affect union formation. However, if we only considered unions with cohabiting children, we would risk relating opportunity structures to the event of a cohabiting couple getting married or having their first child, although they may have been a cohabiting union for several years.

The study population was limited to 1.5 and second-generation immigrants. 1.5 generation immigrants were born in the period from 1966-1986 and were between 0-17 years old when they arrived in Denmark. Moreover, they resided in Denmark at the age of eighteen. Secondgeneration immigrants were defined as children born in Denmark between 1966-1986 to immigrant 
parents, neither of whom were Danish citizens nor were born in Denmark. In total, our study included 535,878 person-years based on 71,122 1.5 and second-generation immigrants from 120 national origin groups.

In the case of country mergers (e.g., East and West Germany) or splits (e.g., Yugoslavia), we coded coherent units that could be retained throughout the period of analysis. The former Soviet Union was merged with 'Russia'. The former Yugoslavia, Serbia, and Montenegro were merged into one unit, 'Serbia Montenegro'. Czechoslovakia was merged with Czech Republic. Finally, East and West Germany were kept together as Germany.

\section{Outcomes}

We consider three types of unions: 1) mixed union with a native (i.e., the partner and his or her parents were born in Denmark), 2) mixed union with an immigrant from another national origin group (i.e., the partner is also an immigrant or second-generation immigrant but he or she or his or her parents came from a different country of origin than the individual), and 3) unmixed union (i.e., the partner is also an immigrant or second-generation immigrant from the same country of origin as the individual).

The individuals in the study population were assumed to enter the risk set upon turning 18 and were not already part of a union. They were followed until they formed their first union or right censoring occurred. Their data were right censored if they died, migrated, reached the age of 40 , or the period of observation ended. We considered only the first union formation and not second- or higher-order union formations. 


\section{Measures for Cultural Proximity}

Our analyses relied on three measures for cultural proximity: religious background, Danish language proficiency, and degree of globalization. These variables were all measured at the national origin group level based on information from the countries of origin.

Christian and Muslim backgrounds are the percentages of the population in the country of origin who were Christian or Muslim, respectively, based on 2010 data from the Pew Research Center (Pew Research Center 2015). Scandinavian language is an indicator variable equal to one if the immigrants or second-generation immigrants were from Sweden, Norway, or Iceland and zero otherwise. Globalization is an index that measures the country of origin's degree of globalization in 2000. The globalization index is based on a range of indicators that proxy a country's degree of economic globalization (e.g., trade flows and trade restrictions), political globalization (e.g., embassies in the country and memberships in international organizations), and social globalization (e.g., outgoing telephone traffic, internet users, number of McDonald's restaurants). For more details on the construction of the globalization index, see Dreher (2006). The most globalized countries in our study were the United States, Canada, Sweden, and Denmark. The least globalized countries in our study were Rwanda, Myanmar, Sierra Leone, and Burundi.

\section{Measures for Opportunity Structures}

A major benefit of the longitudinal approach is that opportunity structures were measured as timevarying variables. As we describe below, this is important because each opportunity structure indicator can change over time due to differences in fertility rates and the influx of new immigrants.

Opportunity structures were captured by demographic characteristics of the national origin groups measured in 11 local partner markets defined as provinces in Denmark. The definition 
of provinces was coded by Statistics Denmark and follows the Nomenclature of Territorial Units for Statistics (NUTS), which is a harmonized method that subdivides EU Member States into territorial units. The eleven provinces of Denmark are classified according to NUTS level 3, where the population threshold as a rule is between 150.000 and 800.000 individuals. The eleven provinces are North Jutland, East Jutland, West Jutland, South Jutland, Funen, Bornholm, West and South Zealand, East Zealand, North Zealand, Copenhagen City, and Copenhagen Surroundings, as shown in Figure 3.

\section{[Figure 3]}

Figure 3. Map of the 11 Provinces in Denmark

Relative group size was measured as a time-varying variable that captures the number of individuals from particular countries of origin per thousand of the population aged 18-40 years in the province. For example, for a 1.5 or second-generation immigrant from Turkey, group size was measured as the number of individuals per thousand of the population aged 18-40 in the individuals' province of residence who were immigrants or second-generation immigrants from Turkey. The sex ratio was measured as the proportion of men aged 18-40 divided by the proportion of women aged 18-40 in the national origin group in the province of residence multiplied by 100 . Consequently, a number greater than 100 indicates that there were more men than women in the national origin group in the local partner market. Conversely, a number smaller than 100 indicates that there were more women than men in the national origin group in the province of residence. Educational similarity is the percentage of all opposite-sex members aged 25-40 in the national origin group who have the same educational level as the individual in the province of residence. We distinguish three levels: 1) no education leading to a vocational/professional qualification, 2) vocational or short tertiary education, and 3) medium or higher tertiary education. 


\section{Individual-level Control Variables}

To account for compositional differences between the national origin groups, we controlled for a number of individual factors, including the first year of observation, generational status, and educational attainment. The first year of observation is a set of indicator variables that indicate the first year the individual was observed in the dataset; this is equivalent to the year in which the individual turned eighteen within the period of investigation. The first year of observation was controlled for partly to purge a possible period effect and partly to account for changes in family reunification rules during the period of investigation. These changes tightened the rules for non-EU immigrants who planned to seek asylum-based or family-based residence. This implies that immigrants and second-generation immigrants observed in recent periods were subject to tighter family reunification rules than those observed in earlier periods. The most far-reaching of these changes, the '24-year rule', was introduced in 2002. This rule dictated that both spouses must be at least 24 years old to obtain marriage-based residency. The aim of this change was to reduce the possibility for young immigrants to import spouses because of concern regarding forced marriages. Empirical evidence on the effect of the '24-year rule' suggests that the proportion of non-Western immigrants who got married between the ages of 18 and 24 years dropped significantly after the implementation of the rule (Schultz-Nielsen and Tranæs 2009).

Generational status was controlled for because second-generation immigrants are expected to be more likely to form mixed unions with the native population than 1.5 generation immigrants (Andersson, Obućina, and Scott 2015; Dribe and Lundh 2011). Moreover, the generational composition of a national origin group depends on its immigration history. Because immigrants from Turkey, the former Yugoslavia, and Pakistan arrived in the 1960s, we find larger 
proportions of second-generation immigrants in these groups than in other national origin groups in Denmark. Among 1.5 generation immigrants, we distinguished between immigrants who were 1) 05 years old, 2) 6-11 years old, and 3) 12-17 years old when they arrived because we expected those who were younger when they arrived to be more likely to form mixed unions with the native population than those who were older. Moreover, we included a separate indicator variable equal to one if information regarding age on arrival was missing (1\%) and zero otherwise. Following the classification of Statistics Denmark, an immigrant is defined as a person who is born outside Denmark and whose parents are not Danish citizens or were born outside Denmark. A secondgeneration immigrant is defined as a person who is born in Denmark and whose parents are immigrants or immigrant descendants who are not Danish citizens. In our analysis, we retained the immigrant's generational status from age 18 and onwards. This means that in the rare event that one of the parents of a second-generation immigrant is granted citizenship during the period of investigation, the second-generation immigrant does not change generational status.

Educational attainment was controlled for because 1.5 and second-generation immigrants with a higher educational level are expected to be more likely to intermarry with the native population. There are several reasons for this. First, evidence suggests that educational attainment is associated with a weaker preference for a partner based on ascribed characteristics such as national origin or ethnicity (van Tubergen and Maas, 2006). Second, the native Danish population is, on average, highly educated, suggesting that highly educated immigrants will be more attractive partners for the native population (Elwert, 2020). Education was coded as a time-varying variable that indicates the individual's highest level of educational attainment in six groups: 1) primary/secondary education, 2) gymnasium/high school, 3) vocational education, 4) short-cycle tertiary, 5) medium-cycle tertiary, and 6) long-cycle tertiary. Unfortunately, information about 
education was missing for approximately 20 percent of the analysis sample. We therefore included education: missing as a separate category.

Table 1 provides descriptive statistics for all variables in our models.

\section{[Table 1]}

\section{Analytical Strategy}

In our multivariable analysis, we used multilevel discrete-time event history analysis because union formation is an event and because we include variables at different levels. We estimated two-level models with immigrants and second-generation immigrants (level 1) nested in national origin groups (level 2). After the data are restructured into person-period format, the model can be fitted as separate multilevel logistic regression in which time is included as a covariate (Steele 2008).

Because we considered transitions from being single to three different types of unions (i.e., mixed union with a native, mixed union with another immigrant, unmixed union), we relied on a competing risks approach.

We used a multivariate binary response approach to set up our competing risks model. In a multivariate binary response approach, a set of independent binary logistic regression models are used to model event-specific discrete-time hazards (Steele 2011). In this case, event-specific discrete-time hazards can be defined as the probability that individual $i$ belonging to group $g$ residing in province $p$ experiences event type $r$ rather than any other event in time interval $t$ or is censored (i.e., they died, migrated, reached the age of 40, or the period of observation ended) given that no event occurred before the start of $t$, i.e., $p_{\text {tigp }}^{(r)}=\operatorname{Pr}\left(y_{\text {tigp }}=r \mid y_{t-1, i g p}=0\right), r=1,2,3$. Under the assumptions of independent and noninformative censoring (i.e., the censoring mechanism does not depend on the times to the events or on their distributions), we used three separate multilevel logistic regression models to model the event-specific discrete-time hazards: 
$\log \left(\frac{p_{\text {tigp }}^{(r)}}{1-p_{\text {tigp }}^{(r)}}\right)=\alpha_{0}^{(r)}+\alpha_{1}^{(r)} t+\alpha_{1}^{(r)} t^{2}+\boldsymbol{\beta}^{(r)} \mathbf{x}_{\text {tigp }}+\boldsymbol{\gamma}^{(r)} \mathbf{c}_{g}+\boldsymbol{\theta}^{(r)} \mathbf{o}_{\text {tigp }}+s y_{t}^{(r)}+v_{p}^{(r)}+u_{g}^{(r)}+\varepsilon_{\text {tigp }}, \quad r=1,2,3$

where the baseline logit hazard was modeled as a function of $t$ and $t^{2}$ because most people marry in their mid-twenties, implying that the baseline logit hazard is inversely U-shaped. Moreover, $\mathbf{x}_{\text {tigp }}$ is a vector of individual-level covariates, $\mathbf{c}_{g}$ is a vector of cultural factors that vary only by national origin groups, $\mathbf{0}_{\text {tigp }}$ is a vector of opportunity structures, $s y_{t}$ are indicators for starting year, $v_{p}$ are indicators for province, $u_{g}$ is a random intercept across national origin groups, and $\varepsilon_{\text {tigp }}$ is an error term. It should be noted that only one of the opportunity structure variables, namely, educational similarity, varies between individuals, as indicated in our model. The other opportunity structure variables, group size and sex ratio, vary only over time, across national origin groups, and across provinces. The opportunity structure variables were measured by January 1 in $t$, meaning that opportunity structures measured on the first day of the year were related to unions that were formed at some point during the following year.

Because we implemented the competing risks model with a multivariate binary response approach rather than with a multinomial logistic regression approach, the estimated coefficients provide associations between the included variables and the log-odds of a specific event relative to the reference category 'no event of that specific type'. If we had instead implemented the competing risks model with a multinomial logistic regression, the reference category would be 'no event'. While the two approaches are frequently used interchangeably, we preferred the multivariate binary response approach because the estimated event-specific coefficients in this approach are independent of the composition of the other events. This is important because the division between mixed union formation with another immigrant and unmixed union formation is not always clear. For example, our model does not classify unions between Sri Lankans and Indians as unmixed, 
although they may both descend from the same South Indian state, Tamil Nadu. Consequently, the multinomial approach risks underestimating the likelihood of mixed union formation with native persons and/or unmixed union formation depending on the proportion of immigrants and secondgeneration immigrants from the national origin group who form mixed unions with immigrants or second-generation immigrants from another group.

We estimated separate models for men and women because union formation patterns of 1.5 and second-generation immigrants in Denmark have been found to differ by gender (SchultzNielsen 2021).

\section{Results}

We begin our analysis by presenting descriptive results on mixed and unmixed union rates across the national origin groups. Table 2 shows the share of 1.5 and second-generation immigrants who formed a mixed union with a native, formed a mixed union with another immigrant, formed an unmixed union, or were censored (i.e., they died, migrated, reached the age of 40, or the period of observation ended) by country of origin in the period from 1986-2016. The table shows that there were large differences in the rates of mixed and unmixed unions across the national origin groups. Generally, we find a higher proportion of mixed unions in the Western national origin groups than in the non-Western national origin groups, but there is also large variation within these broad categorizations. The lowest rates of mixed unions with the native population are found in the Turkish, Pakistani, and Somali national origin groups. In these groups, 8 percent of the members formed a mixed union with a native during the period of investigation with the rate being higher for men than for women. We also found high rates of unmixed union formation within these groups, as 68, 52, and 37 percent of Turkish, Pakistani, and Somali national origin groups, respectively, 
formed unmixed unions during the period of investigation. Other groups with high rates of unmixed union formation were the Vietnamese and Sri Lankan national origin groups, as 49 and 44 percent formed unmixed unions, respectively. The highest rates of mixed union formation with the native population were found in the Swedish, Polish, and Dutch national origin groups. In these groups, 59,56 , and 53 percent of the members formed mixed unions with natives during the period of investigation, respectively.

[Table 2]

As shown in Table 3, there are stark differences in the proportions of union formations that resulted from nonmarital cohabitation and legal marriages. Out of all unmixed union formations, almost two-thirds resulted from legal marriages. In contrast, out of all mixed union formations that included a native only about one out of twenty and one out of ten resulted from legal marriages while the vast majority resulted from cohabitation without common children. This pattern suggests that while nonmarital cohabitation is common among immigrants who form unions with natives, legal marriage remains the dominant living arrangement among immigrants who form unions within their own group.

[Table 3]

\section{Multivariable Results}

In Table 4, we present the results of multilevel discrete-time event history analyses that predict the likelihood of mixed and unmixed union formation for men and women. Except for binary variables, all variables were standardized to allow the comparison of coefficient sizes.

To test the assumption that opportunity structures are better measured in local partner markets rather than in a single national partner market, we ran likelihood-ratio tests between models in which opportunity structures are measured in local partner markets and province indicator 
variables are included (as shown in Table 4) and reduced models in which opportunity structures are measured at the national level and province indicator variables are not included (see Table A1 in the online supplemental material). Overall, this analysis suggests that the local partner market models provided significantly better model fits than the national partner market models. However, the differences in model fits are much greater for mixed union formation with a native than for unmixed union formation. This suggests that opportunity structures in local partner markets have a stronger bearing on the likelihood of mixed union formation than on the likelihood of unmixed union formation. The reason for this is possibly that 1.5 and second-generation immigrants who search for a partner from their own national origin group are often willing to expand their search beyond the local partner market, while 1.5 and second-generation immigrants who might form a mixed or unmixed union dependent on who they happen to meet at the right time are more strongly affected by the opportunity structures in their local partner market. Actually, when considering the event of unmixed union formation, it is only for women that the local partner model provides a significantly better model fit than the national partner market model. Nevertheless, to keep our presentation parsimonious, we present only the results from local partner market models in the following sections because they generally provide better model fits. However, the results from national partner market models are available in Table A2 in the online supplemental material. Next, as expected, we note that the coefficients for time and time squared suggest that the relationship between time and union formation is inverse U-shaped, meaning that the likelihood of forming one's first union generally increases from age eighteen until approximately the mid-twenties, after which it levels off.

The Role of Cultural Factors 
We now proceed to discuss the associations between cultural factors and the likelihood of mixed and unmixed union formation. As expected, Table 4 suggests that religious background is strongly associated with the likelihood of mixed and unmixed union formation. The standardized coefficients suggest that religious background is the strongest predictor of mixed union formation with the native population. For men and women, the coefficients indicate that a one standard deviation increase in the share of Christians in the country of origin is associated with a 34 and 18 percent increase in the odds of mixed union formation with the native population, respectively. Moreover, for women, the results suggest that a one standard deviation increase in the share of Muslims in the national origin groups is associated with a 39 percent decrease in the odds of mixed union formation with the native population and a 63 percent increase in the odds of unmixed union formation. For men, on the other hand, we find no evidence that the share of Muslims in the country of origin is associated with the likelihood of mixed and unmixed union formation.

Next, in the analysis sample of 1.5 and second-generation immigrants, who can be expected to speak Danish themselves, we find no evidence that familiarity with a Scandinavian language is associated with the likelihood of mixed and unmixed union formation, except that for men, it appears to slightly decrease the likelihood of mixed union formation with another immigrant.

Finally, we inspect the coefficients for the globalization index. We find no evidence that the degree of globalization in 1.5 and second-generation immigrants' countries of origin is associated with a higher likelihood of mixed union formation with a native. However, a one standard deviation increase in the globalization index is associated with a 31 and 33 percent decrease in the likelihood of unmixed union formation for men and women, respectively. 


\section{The Role of Opportunity Structures}

Next, we examine the coefficients for the opportunity structures. We begin by examining the role of group size. As expected, the results suggest that national origin group size is inversely related to the odds of mixed union formation with the native population. The results suggest that a one standard deviation increase in the relative group size of the national origin group in 1.5 or second-generation immigrants' local partner market is associated with 13 and 25 percent decreases in the odds of mixed union formation with a native for men and women, respectively. Moreover, we find that a one standard deviation increase in group size is associated with 5 and 11 percent increases in the odds of unmixed union formation for men and women, respectively.

For men, a skewed sex ratio within the national origin group is also modestly related to the likelihood of mixed union formation with a native. For men, a one standard deviation increase in the sex ratio, indicating that there are more men than women in the national origin group in the local partner market, is associated with a 3 percent increase in the odds of mixed union formation with a native and a 14 percent decrease in the odds of unmixed union formation. For women, we find no evidence that a skewed sex ratio is related to the likelihood of mixed or unmixed union formation.

Last, we find evidence that within-group educational similarity is related to union formation. For men, we find no evidence that within-group educational similarity is related to mixed union formation, but a one standard deviation increase in within-group educational similarity in the local partner market is associated with a 28 percent increase in the odds of unmixed union formation. For women, a one standard deviation increase in within-group educational similarity in 
the local partner market is associated with a 9 percent decrease in the odds of mixed union formation with a native and a 14 percent increase in the odds of unmixed union formation.

\section{The Role of Compositional Differences}

Although our main focus is on the role of group-level cultural characteristics and opportunity structures in partner markets, we briefly discuss the role of individual-level factors. As expected, the results suggest that immigrants who arrived in their teens (aged 12-17) were less likely to form a mixed union with a native and more likely to form an unmixed union than second-generation immigrants were. Moreover, inspecting the coefficients for education, we learn that immigrants who were higher educated were more likely to form a mixed or unmixed union than their less educated counterparts, reflecting that higher education increases the likelihood of finding a partner and highlights the importance of accounting for right censoring.

\section{The Relative Importance of Cultural Factors and Opportunity Structures}

The foregoing analysis has revealed that there are marked differences in the likelihood of mixed and unmixed union formation between national origin groups depending on both individual factors and group-level factors, including culture and opportunity structures. However, this tells us little about the relative importance of cultural factors and opportunity structures in terms of explaining grouplevel differences in the likelihood of mixed and unmixed union formation.

We therefore decompose the residual group-level variance in mixed and unmixed union formation into parts explained by cultural factors and opportunity structures. We do so by comparing group-level variances between models that only include cultural factors or opportunity 
structures. Although our procedure should give us an indication about the relative importance of cultural factors and opportunity structures, it is not without limitations. First, unlike in linear multilevel models, the individual-level variance is fixed at 3.29 in multilevel logistic regressions because the standard logistic distribution is assumed. This implies that the individual-level variance cannot decrease as individual-level covariates are added to the model, meaning that the separation between individual- and group-level variance is not straightforward. Nevertheless, the decomposition provides an indication of the relative importance of cultural and structural factors.

The results of the decomposition are shown in Table 5. In total, individual, cultural, and structural factors explain approximately 60 and 69 percent of the group-level variance in mixed union formation for men and women, respectively, and 45 and 52 percent of the group-level variance in unmixed union formation. However, inspecting the residual group-level variances from reduced models, we learn that cultural factors explain the vast majority of group-level differences in inter- and unmixed union formation and much more than structural factors.

The results thus suggest that adding individual factors to the empty models explains very little of the group-level variance. In some cases, the group-level variance even appears to increase when individual covariates are added. However, when cultural factors are included in addition to the individual factors, the model explains approximately 54 and 65 percent of the grouplevel variance in mixed union formation with natives for men and women, respectively, and approximately 40 and 47 percent of the group-level variance in unmixed union formation. Comparatively, the model that includes opportunity structures in addition to individual factors explains only approximately 17 and 14 percent of the group-level variance in mixed union formation with natives for men and women, respectively, and none of the group-level variance in unmixed union formation for men or women. 
[Table 5]

\section{Discussion and Conclusion}

In this study, we examined to what extent differences in union formation patterns among 1.5 and second-generation immigrants in Denmark depending on national origin groups were explained by cultural proximity to the receiving country or by opportunity structures in local partner markets. Using a longitudinal dataset based on information from administrative registers, our study followed $71,1221.5$ and second-generation immigrants from 120 different national origin groups residing in 11 local partner markets in Denmark. To analyze the data, we used multilevel discrete-time event history models that address both right censoring and time-varying covariates.

Our results suggest that differences in the likelihood of mixed union formation among 1.5 and second-generation immigrants are explained in part by cultural factors, such as religion, language, and degree of globalization, and in part by the opportunity structures in the local partner markets, such as group size, sex ratio, and within-group educational similarity. However, similar to what Kalmijn and van Tubergen (2010) found in the American case, our findings suggest that cultural factors explain a much larger proportion of the group-level variation in mixed and unmixed union formation than opportunity structures do; this is also the case when the time-varying nature of opportunity structures are accounted for. Moreover, the fact that Kalmijn and van Tubergen's conclusion that was based on evidence from the United States was corroborated in a country with a highly different immigration history, such as Denmark, suggests that it is highly generalizable.

While we corroborated Kalmijn and van Tubergen's overall conclusion that cultural factors explain a larger proportion of the group-level variation in mixed and unmixed union formation than opportunity structures do, our findings also suggest that opportunity structures in local partner markets have a stronger bearing on the likelihood of mixed union formation than on 
unmixed union formation. One likely reason for this is that 1.5 and second-generation immigrants who have strong preferences for a partner from their own national origin group do not limit their search for a partner to local partner markets.

As with any study, however, our research is not without limitations. First, to include nonmarital cohabiting unions without common children, we relied on a proxy variable. According to this proxy, two people of different sexes whose age difference is less than fifteen years who share the same address without being related to each other by kinship are considered a cohabiting couple. In rare cases, this proxy may misclassify roommates as cohabiting couples. However, we consider this a necessary evil because our results suggests that we would severely underestimate immigrants' likelihood of mixed union formation with a native if we only considered legal marriages. The reason for this is that nonmarital cohabitation is by far the most common living arrangement among immigrants who form mixed unions with natives. In contrast, legal marriage remains the most common living arrangement among immigrants who have formed unmixed unions. Second, to account for differences in opportunity structures across partner markets, we assumed that provinces in Denmark serve as proxies for local partner markets. These provinces are certainly not perfect proxies but evidence from Sweden suggests that although the distance between partners has increased over time due to increased mobility and technological development, most people still find their partners near where they live (Haandrikman, 2019). Third, the information on cultural proximity was based on information from the 1.5 and second-generation immigrants' countries of origin. While this information proxies the cultural background of 1.5 and second-generation immigrants, this information may not accurately describe the group in Denmark to varying degrees because evidence suggests that immigrants are often a selected subsample of the population in the country of origin (Ichou 2014). Clearly, it would improve our analysis if we were able to include individual-level information about cultural factors, such as religion. However, the absence of such 
information is the price we pay for being able to construct a large longitudinal dataset covering the whole population based solely on administrative register data. Fourth, we did not include information about the reasons for immigration. The consequences of this shortcoming, however, should be reduced by the fact that we restricted our population to childhood immigrants and secondgeneration immigrants. Nevertheless, whether the parents of the childhood immigrants and secondgeneration immigrants were refugees or immigrants may play a role. Fifth, although a major strength of our approach is that we address right censoring, our approach relies on the assumption that right censoring is uninformative. However, one particular concern for which we saw no remedy is that some 1.5 and second-generation immigrants may have moved abroad to marry someone from their own country of origin. Consequently, in national origin groups where this occurs, we might to some extent underestimate the likelihood of unmixed union formation because we observe only unions that were formed in Denmark. Sixth, while cultural proximity theory recognizes the relational nature of the incorporation process, we focused mainly on 'the immigrant side' of the question. In particular, we did not include measures that capture possible differences in the perceived social status of different national origin groups among natives in the local partner markets, although differences in mixed and unmixed union formation rates among immigrants have been linked to group-level differences in social status (Elwert 2020).

Despite these limitations, we believe our study provides an important contribution to discussions about why 1.5 and second-generation immigrants from some national origin groups are more likely to form mixed unions with natives or with other immigrants in a receiving country than others. 


\section{References}

Alba, R., B. Beck, and D. B. Sahin. 2018. “The U.S. Mainstream Expands-Again.” Journal of Ethnic and Migration Studies 44(1): 99-117.

Alba, R. and V. Nee. 1997. "Rethinking Assimilation Theory for a New Era of Immigration." International Migration Review 31(4): 826-74.

Allport, G. W. 1954. The Nature of Prejudice. Reading, MA: Addison-Wesley.

Andersson, G., O. Obućina, and K. Scott. 2015. "Marriage and Divorce of Immigrants and Descendants of Immigrants in Sweden.” Demographic Research 33(1): 31-64.

Blau, P. M. 1977. Inequality and Heterogeneity. New York: Free Press.

Blau, P. M., T. C. Blum, and J. E. Schwartz. 1982. "Heterogeneity and Intermarriage.” American Sociological Review 47(1): 45-62.

Blossfeld, H-P. 2009. "Educational Assortative Marriage in Comparative Perspective.” Annual Review of Sociology 35(1): 513-30.

Carol, S. 2013. "Intermarriage Attitudes among Minority and Majority Groups in Western Europe: The Role of Attachment to the Religious in-Group." International Migration 51(3): 67-83.

Carol, S., E. Ersanilli, and M. Wagner. 2014. "Spousal Choice among the Children of Turkish and Moroccan Immigrants in Six European Countries: Transnational Spouse or Co-Ethnic Migrant?” International Migration Review 48(2): 387-414.

Dreher, A. 2006. "Does Globalization Affect Growth? Evidence from a New Index of Globalization." Applied Economics 38(10): 1091-1110.

Dribe, M. and C. Lundh. 2011. "Cultural Dissimilarity and Intermarriage. A Longitudinal Study of 
Immigrants in Sweden 1990-2005.” International Migration Review 45(2): 297-324.

Drouhot, L. G. 2021. "Cracks in the Melting Pot? Religiosity and Assimilation among the Diverse Muslim Population in France.” American Journal of Sociology 126(4): 795-851.

Drouhot, L. G. and V. Nee. 2019. "Assimilation and the Second Generation in Europe and America: Blending and Segregating Social Dynamics between Immigrants and Natives.” Annual Review of Sociology 45:177-99.

DST. 2018. Indvandrere i Danmark 2018 (Revideret Udgave) [Immigrants in Denmark 2018 (Revised Edition]. Copenhagen: Statistics Denmark.

Elwert, A. 2020. “Opposites Attract: Assortative Mating and Immigrant-Native Intermarriage in Contemporary Sweden.” European Journal of Population 36: 675-709.

Elwert, A. and A. Tegunimataka. 2016. "Cohabitation Premiums in Denmark: Income Effects in Immigrant-Native Partnerships.” European Sociological Review 32(3): 383-402.

Gans, H. J. 1992. "Comment: Ethnic Invention and Acculturation, a Bumpy-Line Approach.” Journal of American Ethnic History 12(1):42-52.

Gordon, M. M. 1964. Assimilation in American Life: The Role of Race, Religion, and National Origins. New York: Oxford University Press.

Haandrikman, Karen. 2019. "Partner Choice in Sweden: How Distance Still Matters”. Environment and Planning A: Economy and Space 51(2): 440-460.

Harris, D. R. and H. Ono. 2005. "How Many Interracial Marriages Would There Be If All Groups Were of Equal Size in All Places? A New Look at National Estimates of Interracial Marriage.” Social Science Research 34(1): 236-51. 
Ichou, M. 2014. “Who They Were There: Immigrants' Educational Selectivity and Their Children's Educational Attainment.” European Sociological Review 30(6): 750-65.

Kalmijn, M. 1998. "Intermarriage and Homogamy: Causes, Patterns, Trends.” Annual Review of Sociology 24(1): 395-421.

Kalmijn, M. and F. van Tubergen. 2010. “A Comparative Perspective on Intermarriage: Explaining Differences among National-Origin Groups in the United States." Demography 47(2): 459-79.

Kulu, H. and A. Gonzalez-Ferrer. "Family Dynamics Among Immigrants and Their Descendants in Europe: Current Research and Opportunities” European Journal of Population 30(4): 411-435.

Kulu, H. and T. Hannemann. "Mixed Marriage among Immigrants and Their Descendants in the United Kingdom: Analysis of Longitudinal Data with Missing Information” Population Studies 73(2): 179-196

Lanzieri, G. 2012. “Mixed Marriages in Europe, 1990-2010.” Pp. 81-121 in Cross-border Marriage: Global Trends and Diversity, edited by D.-S. Kim. Seoul: Korea Institute for Health and Social Affairs.

Lichter, D. T., J. H. Carmalt, and Z. Qian. 2011. "Immigration and Intermarriage Among Hispanics: Crossing Racial and Generational Boundaries.” Sociological Forum 26(2): 241-64.

Lichter, D. T., Z. Qian, and D. Tumin. 2015. "Whom Do Immigrants Marry? Emerging Patterns of Intermarriage and Integration in the United States." The ANNALS of the American Academy of Political and Social Science 662(1): 57-78.

Lodberg, P. 2000. "Freedom of Religion and the Evangelical Lutheran Church in Denmark." Studia Theologica - Nordic Journal of Theology 54(1): 43-54.

Lucassen, L. and C. Laarman. 2009. “Immigration, Intermarriage and the Changing Face of Europe 
in the Post War Period." History of the Family 14(1): 52-68.

Lund, R. L., A. Jørgensen, and O. P. Riis. 2019. "Social Geographical Patterns in Membership of the Established Church in Denmark." Nordic Journal of Religion and Society 32(1): 55-70.

Mare, R. D. 1991. "Five Decades of Educational Assortative Mating.” American Sociological Review 56(1): 15-32.

Muttarak, R. and A. Heath. 2010. "Who Intermarries in Britain? Explaining Ethnic Diversity in Intermarriage Patterns.” British Journal of Sociology 61(2): 275-305.

Nusche, D., G. Wurzburg, and B. Naughton. 2010. OECD Reviews of Migrant Education: Denmark. Paris: OECD.

Pettigrew, T. F. 1998a. “Intergroup Contact Theory.” Annual Review of Psychology 49: 65-85.

Pettigrew, T. F. 1998b. "Reactions toward the New Minorities of Western Europe.” Annual Review of Sociology 24: 77-103.

Pew Research Center. 2015. Religious Composition by Country, 2010-2050. Retrieved from http://www.pewforum.org/2015/04/02/religious-projection-table/2010/number/all/

Putnam, R. D. 2007. "E Pluribus Unum: Diversity and Community in the Twenty First Century the 2006 Johan Skytte Prize Lecture.” Scandinavian Political Studies 30(2): 137-74.

Qian, Z. and D. T. Lichter. 2007. "Social Boundaries and Marital Assimilation: Interpreting Trends in Racial and Ethnic Intermarriage.” American Sociological Review 72(1): 68-94.

Rumbaut, R. G. 2001. “Assimilation of Immigrants.” Pp. 845-49 in International Encyclopaedia of the Social and Behavioral Sciences, vol. 2, edited by Neil J. Smelser and Paul B. Baltes. Amsterdam: Elsevier. 
Rumbaut, R. G. 2012. “Generation 1.5, Educational Experiences of”. In Encyclopedia of Diversity in Education, edited by James A. Banks. Thousand Oaks, CA: Sage Publications

Schmidt, G. and V. Jakobsen. 2004. Pardannelse Blandt Etniske Minoriteter [Couple Formation among Ethnic Minorities]. Copenhagen: Socialforskningsinstituttet.

Schultz-Nielsen, M. L. and T. Tranæs. 2009. Agteskabsmønstret for Unge Med Indvandrerbaggrund: Konsekvenser Af Andringer i Udlandingeloven i 2000 Og 2002 [Marital Patterns Among Young People with an Immigrant Background: Consequences of Changes in the Foreigner Legislation in 2000 and 2002]. Copenhagen: Rockwool Fondens Forskningsenhed.

Schultz-Nielsen, M. L. 2021. Uddannelsesmønster Blandt Unge Med Indvandrerbaggrund Udviklingen i $25 \AA$ Ar [Educational Patterns among Young People with Immigrant Background Trends over 25 Years]. Copenhagen: Rockwool Fondens Forskningsenhed.

Schwartz, C. R. and R. D. Mare. 2005. "Trends in Educational Assortative Marriage from 1940 to 2003." Demography 42(4): 621-46.

Spörlein, C., E. Schlueter, and F. van Tubergen (2014). "Ethnic Intermarriage in a Longitudinal Perspective: Testing Structural and Cultural Explanations in the United States, 1880-2011.” Social Science Research 43: 1-15

Steele, F. 2008. "Multilevel Models for Longitudinal Data." Journal of the Royal Statistical Society. Series A: Statistics in Society 171(1):5-19.

Steele, F. 2011. "Multilevel Discrete-Time Event History Models with Applications to the Analysis of Recurrent Employment Transitions." Australian and New Zealand Journal of Statistics 53(1):1-20. 
Strabac, Z. and O. Listhaug. 2008. "Anti-Muslim Prejudice in Europe: A Multilevel Analysis of Survey Data from 30 Countries.” Social Science Research 37(1):268-86.

Togeby, L. 1998. "Prejudice and Tolerance in a Period of Increasing Ethnic Diversity and Growing Unemployment: Denmark since 1970.” Ethnic and Racial Studies 21(6):1137-54.

Triandis, H. C. 1994. Culture and Social Behavior. New York, NY: McGraw-Hill.

Van Leeuwen, M. H. D., I. Maas, S. Hin, and K. Matthijs. 2019. "Socio-Economic Modernization and Enduring Language Barriers: Choosing a Marriage Partner in Flemish Communities, 1821-1913." The History of the Family 24(1): 94-122.

Van Tubergen, F. and I. Maas. 2006. "Ethnic intermarriage among immigrants in the Netherlands: An analysis of population data.” Social Science Research 36(2): 1065-1086.

Voas, D. 2009. “The Rise and Fall of Fuzzy Fidelity in Europe.” European Sociological Review 25(2):155-68.

Voas, D. and F. Fleischmann. 2012. "Islam Moves West: Religious Change in the First and Second Generations.” Annual Review of Sociology 38: 525-45.

Warner, W. L. and L. Srole. 1945. The Social Systems of American Ethnic Groups. New Haven, CT: Yale University Press. 
Table 1. Descriptive statistics measured the last year before event/censoring.

\begin{tabular}{lcccc}
\hline & \multicolumn{2}{c}{ Men } & Moan & SD \\
\cline { 2 - 5 } & Mean & SD & & \\
\hline Individual level variables: & & & & \\
$\quad$ Generational status & 0.31 & 0.46 & 0.33 & 0.47 \\
$\quad$ Descendant & 0.13 & 0.34 & 0.13 & 0.34 \\
$\quad$ Immigrant: 0-5 years & 0.24 & 0.42 & 0.23 & 0.42 \\
Immigrant: 6-11 years & 0.31 & 0.46 & 0.29 & 0.46 \\
Immigrant: 12-16 years & 0.01 & 0.10 & 0.01 & 0.11 \\
$\quad$ Immigrant: Unknown & & & & \\
Education & 0.45 & 0.50 & 0.42 & 0.49 \\
Primary/secondary & 0.14 & 0.35 & 0.17 & 0.38 \\
Gymnasium / high school & 0.12 & 0.33 & 0.10 & 0.30 \\
Vocational education & 0.02 & 0.14 & 0.02 & 0.13 \\
Short tertiary & 0.02 & 0.15 & 0.04 & 0.19 \\
Medium tertiary & 0.05 & 0.21 & 0.05 & 0.22 \\
Higher tertiary & 0.20 & 0.40 & 0.20 & 0.40 \\
Education: Missing & & & & \\
Cultural factors: & 29.06 & 36.06 & 31.03 & 36.94 \\
$\quad$ Share of Christians & 56.83 & 43.53 & 54.49 & 43.92 \\
$\quad$ Share of Muslims & 0.03 & 0.18 & 0.04 & 0.19 \\
Scandinavian language & 2.96 & 1.00 & 3.02 & 1.04 \\
$\quad$ Globalization & & & & \\
Opportunity structures & 9.31 & 12.14 & 9.01 & 11.83 \\
$\quad$ Relative group size & 105.66 & 37.77 & 102.45 & 33.26 \\
$\quad$ Sex ratio & 59.05 & 23.83 & 57.70 & 24.07 \\
$\quad$ Educational similarity & 37829 & & 33293 & \\
$N$ & & & & \\
\hline
\end{tabular}


Table 2. The share of immigrants who formed mixed unions, unmixed unions, or were censored by national origin group during the 1986-2016 period in percent.

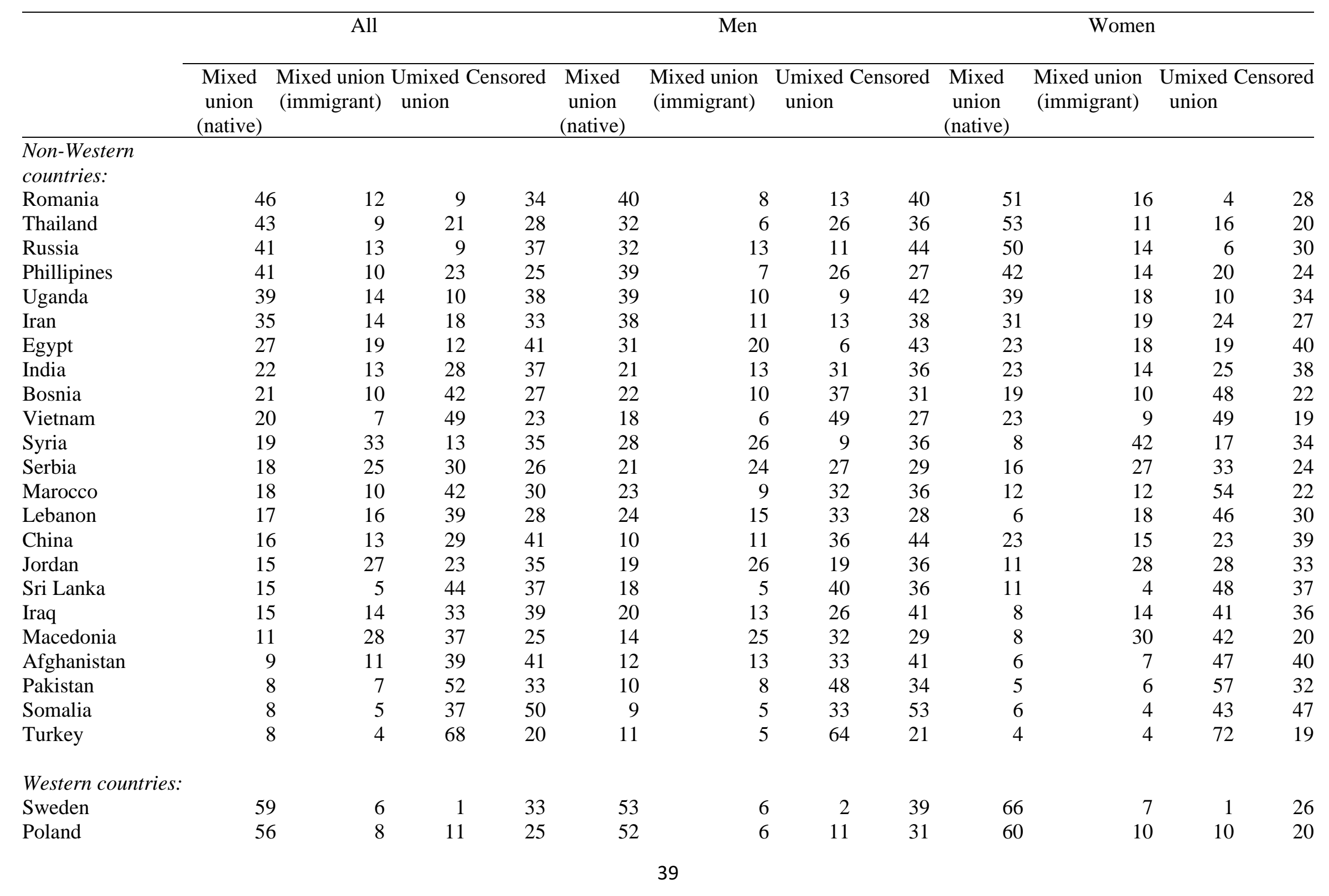




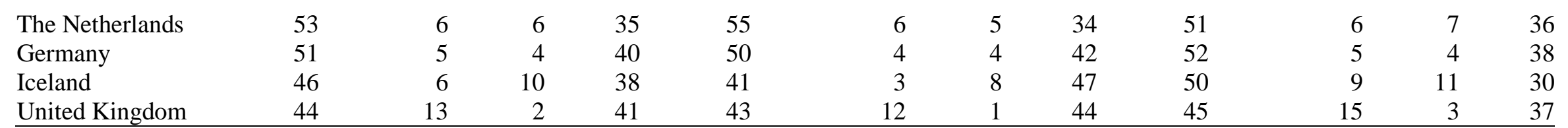

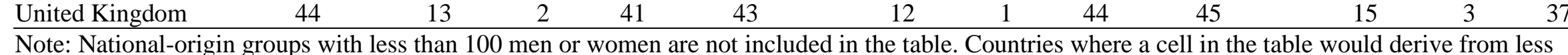
than 5 individuals are not shown in the table. 
Tabel 3. The proportion of all union formations that resulted from marriage, cohabitation with common children, and cohabitation (without common children) in percent

\begin{tabular}{ccccccc}
\hline & \multicolumn{3}{c}{ Men } & & \multicolumn{2}{c}{ Women } \\
\cline { 2 - 7 } & $\begin{array}{c}\text { Mixed union } \\
\text { (native) }\end{array}$ & $\begin{array}{c}\text { Mixed union } \\
\text { (immigrant) }\end{array}$ & Unmixed & $\begin{array}{c}\text { Mixed union } \\
\text { (native) }\end{array}$ & $\begin{array}{c}\text { Mixed union } \\
\text { (immigrant) }\end{array}$ & Unmixed union \\
\hline Marriage & 4.83 & 36.47 & 64.66 & 9.24 & 37.08 & 63.00 \\
$\begin{array}{c}\text { Cohabitation with } \\
\text { common children } \\
\text { Cohabitation }\end{array}$ & 7.48 & 8.44 & 7.18 & 5.32 & 8.73 & 7.78 \\
\hline Total events & 87.68 & 55.08 & 28.15 & 85.44 & 54.19 & 29.21 \\
\hline
\end{tabular}


Table 4. Discrete-time multilevel event history analyses predicting mixed- and unmixed union formation in a competing risks framework

\begin{tabular}{|c|c|c|c|c|c|c|}
\hline & \multicolumn{3}{|c|}{ Men } & \multicolumn{3}{|c|}{ Women } \\
\hline & $\begin{array}{l}\text { Mixed union } \\
\text { (native) }\end{array}$ & $\begin{array}{l}\text { Mixed union } \\
\text { (immigrant) }\end{array}$ & $\begin{array}{l}\text { Unmixed } \\
\text { union }\end{array}$ & $\begin{array}{l}\text { Mixed union } \\
\text { (native) }\end{array}$ & $\begin{array}{l}\text { Mixed union } \\
\text { (immigrant) }\end{array}$ & $\begin{array}{l}\text { Unmixed } \\
\text { union }\end{array}$ \\
\hline \multicolumn{7}{|l|}{ Individual factors } \\
\hline Time & $\begin{array}{l}1.367^{* * * *} \\
(0.014)\end{array}$ & $\begin{array}{l}1.449^{* * *} \\
(0.022)\end{array}$ & $\begin{array}{l}1.416^{* * *} \\
(0.012)\end{array}$ & $\begin{array}{l}1.172^{* * *} \\
(0.013)\end{array}$ & $\begin{array}{l}1.304^{* * *} \\
(0.021)\end{array}$ & $\begin{array}{l}1.244^{* * *} \\
(0.011)\end{array}$ \\
\hline Time $^{2}$ & $\begin{array}{l}0.984^{* * *} \\
(0.001)\end{array}$ & $\begin{array}{l}0.985^{* * *} \\
(0.001)\end{array}$ & $\begin{array}{l}0.983^{* * * *} \\
(0.000)\end{array}$ & $\begin{array}{l}0.991^{* * * *} \\
(0.001)\end{array}$ & $\begin{array}{l}0.986^{* * *} \\
(0.001)\end{array}$ & $\begin{array}{l}0.985^{* * *} \\
(0.001)\end{array}$ \\
\hline \multicolumn{7}{|l|}{$\begin{array}{l}\text { Generational status } \\
\text { (ref. = descendant) }\end{array}$} \\
\hline Immigrant: $0-5$ years & $\begin{array}{l}1.084^{*} \\
(0.039)\end{array}$ & $\begin{array}{l}1.167^{* *} \\
(0.067)\end{array}$ & $\begin{array}{l}1.138^{* * *} \\
(0.039)\end{array}$ & $\begin{array}{l}1.068 \\
(0.045)\end{array}$ & $\begin{array}{l}1.010 \\
(0.058)\end{array}$ & $\begin{array}{l}1.101^{* *} \\
(0.036)\end{array}$ \\
\hline Immigrant: 6-11 years & $\begin{array}{c}0.967 \\
(0.031)\end{array}$ & $\begin{array}{l}1.174^{* *} \\
(0.060)\end{array}$ & $\begin{array}{l}1.290^{* * *} \\
(0.038)\end{array}$ & $\begin{array}{c}1.017 \\
(0.037)\end{array}$ & $\begin{array}{l}1.203^{* * *} \\
(0.060)\end{array}$ & $\begin{array}{l}1.286^{* * *} \\
(0.037)\end{array}$ \\
\hline Immigrant: $12-16$ years & $\begin{array}{l}0.642^{* * *} \\
(0.023)\end{array}$ & $\begin{array}{l}1.252^{* * * *} \\
(0.066)\end{array}$ & $\begin{array}{l}1.633^{* * * *} \\
(0.048)\end{array}$ & $\begin{array}{l}0.718^{* * * *} \\
(0.028)\end{array}$ & $\begin{array}{l}1.152^{* *} \\
(0.060)\end{array}$ & $\begin{array}{l}1.488^{* * *} \\
(0.044)\end{array}$ \\
\hline \multirow{2}{*}{$\begin{array}{l}\text { Immigrant: Age } \\
\text { missing }\end{array}$} & $0.512^{* * *}$ & 1.226 & 0.781 & $0.377^{* * * *}$ & 0.647 & $0.432^{* * *}$ \\
\hline & $(0.075)$ & $(0.308)$ & $(0.111)$ & $(0.060)$ & $(0.173)$ & $(0.065)$ \\
\hline \multicolumn{7}{|l|}{$\begin{array}{l}\text { Educational level } \\
\text { (ref }=\text { no education) }\end{array}$} \\
\hline High-school & $\begin{array}{l}1.207^{* * *} \\
(0.036)\end{array}$ & $\begin{array}{l}1.063 \\
(0.051)\end{array}$ & $\begin{array}{l}0.859^{* * *} \\
(0.026)\end{array}$ & $\begin{array}{l}1.463^{* * *} \\
(0.048)\end{array}$ & $\begin{array}{l}0.901^{*} \\
(0.041)\end{array}$ & $\begin{array}{c}0.772^{* * *} \\
(0.022)\end{array}$ \\
\hline Vocational training & $\begin{array}{l}1.314^{* * *} \\
(0.074)\end{array}$ & $\begin{array}{l}1.078 \\
(0.102)\end{array}$ & $\begin{array}{l}2.628^{* * *} \\
(0.165)\end{array}$ & $\begin{array}{l}1.178^{*} \\
(0.084)\end{array}$ & $\begin{array}{c}1.041 \\
(0.104)\end{array}$ & $\begin{array}{l}1.900^{* * * *} \\
(0.128)\end{array}$ \\
\hline Short-cycle tertiary & $\begin{array}{c}1.172 \\
(0.108)\end{array}$ & $\begin{array}{l}1.384^{*} \\
(0.184)\end{array}$ & $\begin{array}{l}2.235^{* * *} \\
(0.203)\end{array}$ & $\begin{array}{c}1.239 \\
(0.143)\end{array}$ & $\begin{array}{c}0.961 \\
(0.153)\end{array}$ & $\begin{array}{l}1.748^{* * *} \\
(0.172)\end{array}$ \\
\hline Medium-cycle tertiary & $\begin{array}{l}1.366^{* *} \\
(0.133)\end{array}$ & $\begin{array}{l}1.693^{* * *} \\
(0.232)\end{array}$ & $\begin{array}{l}3.649^{* * *} \\
(0.342)\end{array}$ & $\begin{array}{l}1.457^{* * * *} \\
(0.150)\end{array}$ & $\begin{array}{c}0.954 \\
(0.142)\end{array}$ & $\begin{array}{l}2.267^{* * * *} \\
(0.217)\end{array}$ \\
\hline Long-cycle tertiary & $\begin{array}{l}1.497^{* * * *} \\
(0.107)\end{array}$ & $\begin{array}{l}1.410^{* *} \\
(0.163)\end{array}$ & $\begin{array}{c}2.651^{* * * *} \\
(0.220)\end{array}$ & $\begin{array}{l}1.569^{* * * *} \\
(0.132)\end{array}$ & $\begin{array}{c}0.920 \\
(0.119)\end{array}$ & $\begin{array}{l}1.441^{* * * *} \\
(0.134)\end{array}$ \\
\hline Education missing & $\begin{array}{c}0.943 \\
(0.048)\end{array}$ & $\begin{array}{l}1.348^{* * * *} \\
(0.087)\end{array}$ & $\begin{array}{l}1.560^{* * * *} \\
(0.052)\end{array}$ & $\begin{array}{c}0.722^{* * * *} \\
(0.046)\end{array}$ & $\begin{array}{c}1.138 \\
(0.077)\end{array}$ & $\begin{array}{l}1.245^{* * *} \\
(0.044)\end{array}$ \\
\hline \multicolumn{7}{|l|}{ Cultural factors } \\
\hline Share of Christians & $\begin{array}{l}1.343^{* * * *} \\
(0.081)\end{array}$ & $\begin{array}{c}1.041 \\
(0.085)\end{array}$ & $\begin{array}{c}0.707^{*} \\
(0.102)\end{array}$ & $\begin{array}{l}1.176^{*} \\
(0.083)\end{array}$ & $\begin{array}{c}1.132 \\
(0.097)\end{array}$ & $\begin{array}{c}0.847 \\
(0.123)\end{array}$ \\
\hline Share of Muslims & $\begin{array}{c}0.968 \\
(0.072)\end{array}$ & $\begin{array}{c}1.067 \\
(0.105)\end{array}$ & $\begin{array}{c}1.100 \\
(0.189)\end{array}$ & $\begin{array}{c}0.611^{* * * *} \\
(0.054)\end{array}$ & $\begin{array}{c}1.094 \\
(0.113)\end{array}$ & $\begin{array}{l}1.627^{* *} \\
(0.282)\end{array}$ \\
\hline Scandinavian language & $\begin{array}{c}1.059 \\
(0.041)\end{array}$ & $\begin{array}{c}0.895^{*} \\
(0.050)\end{array}$ & $\begin{array}{c}1.026 \\
(0.107)\end{array}$ & $\begin{array}{c}1.083 \\
(0.052)\end{array}$ & $\begin{array}{c}0.977 \\
(0.054)\end{array}$ & $\begin{array}{c}1.066 \\
(0.109)\end{array}$ \\
\hline Globalization & $\begin{array}{c}1.045 \\
(0.039)\end{array}$ & $\begin{array}{c}0.961 \\
(0.051)\end{array}$ & $\begin{array}{c}0.687^{* * * *} \\
(0.069)\end{array}$ & $\begin{array}{c}1.080 \\
(0.047)\end{array}$ & $\begin{array}{c}0.976 \\
(0.052)\end{array}$ & $\begin{array}{c}0.668^{* * *} \\
(0.065)\end{array}$ \\
\hline \multicolumn{7}{|l|}{ Opportunity structures } \\
\hline Relative group size & $\begin{array}{c}0.874^{* * *} \\
(0.022)\end{array}$ & $\begin{array}{l}0.916^{* *} \\
(0.030)\end{array}$ & $\begin{array}{l}1.054^{* * *} \\
(0.014)\end{array}$ & $\begin{array}{c}0.749^{* * * *} \\
(0.032)\end{array}$ & $\begin{array}{l}0.888^{* *} \\
(0.034)\end{array}$ & $\begin{array}{l}1.109^{* * * *} \\
(0.015)\end{array}$ \\
\hline Sex ratio & $\begin{array}{c}1.026^{*} \\
(0.012)\end{array}$ & $\begin{array}{c}1.015 \\
(0.021)\end{array}$ & $\begin{array}{c}0.864^{* * * *} \\
(0.017)\end{array}$ & $\begin{array}{c}0.974 \\
(0.017)\end{array}$ & $\begin{array}{c}0.996 \\
(0.025)\end{array}$ & $\begin{array}{c}0.998 \\
(0.018)\end{array}$ \\
\hline Educational similarity & $\begin{array}{c}0.974 \\
(0.021) \\
\end{array}$ & $\begin{array}{c}0.957 \\
(0.035) \\
\end{array}$ & $\begin{array}{l}1.277^{* * * *} \\
(0.030)\end{array}$ & $\begin{array}{l}0.912^{* * * *} \\
(0.022)\end{array}$ & $\begin{array}{c}0.961 \\
(0.035) \\
\end{array}$ & $\begin{array}{l}1.135^{* * * *} \\
(0.029) \\
\end{array}$ \\
\hline
\end{tabular}




\begin{tabular}{lcccccc}
\hline Group-level variance & $0.124^{* * *}$ & $0.214^{* * *}$ & $0.805^{* * * *}$ & $0.197^{* * * *}$ & $0.236^{* * *}$ & $0.773^{* * * *}$ \\
& $(0.026)$ & $(0.046)$ & $(0.182)$ & $(0.038)$ & $(0.045)$ & $(0.174)$ \\
$\begin{array}{l}\text { Start year indicator } \\
\text { variables }\end{array}$ & YES & YES & YES & YES & YES & YES \\
$\begin{array}{l}\text { Province indicator } \\
\text { variables }\end{array}$ & YES & YES & YES & YES & YES & YES \\
$\begin{array}{l}\text { Observations } \\
\text { The }\end{array}$ & 316792 & 316792 & 316792 & 219086 & 219086 & 219086 \\
\hline
\end{tabular}

The table reports odds ratios with standard errors in parentheses.

${ }^{*} p<0.05,{ }^{* * *} p<0.01,{ }^{* * *} p<0.001$ (two-tailed tests) 
Table 5. Decomposition of the group-level variance

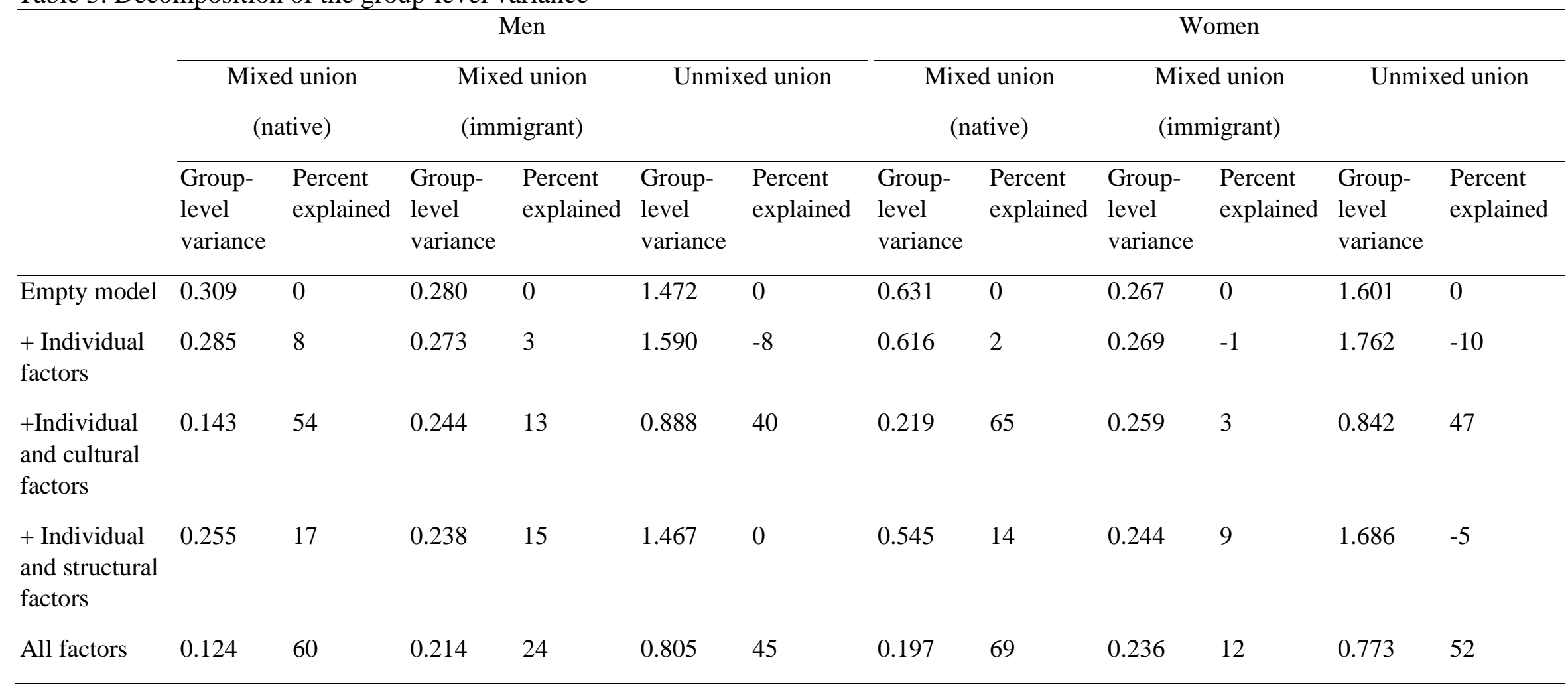


Figure 1. The relative size of the ten largest ethnic groups from Western countries in Denmark

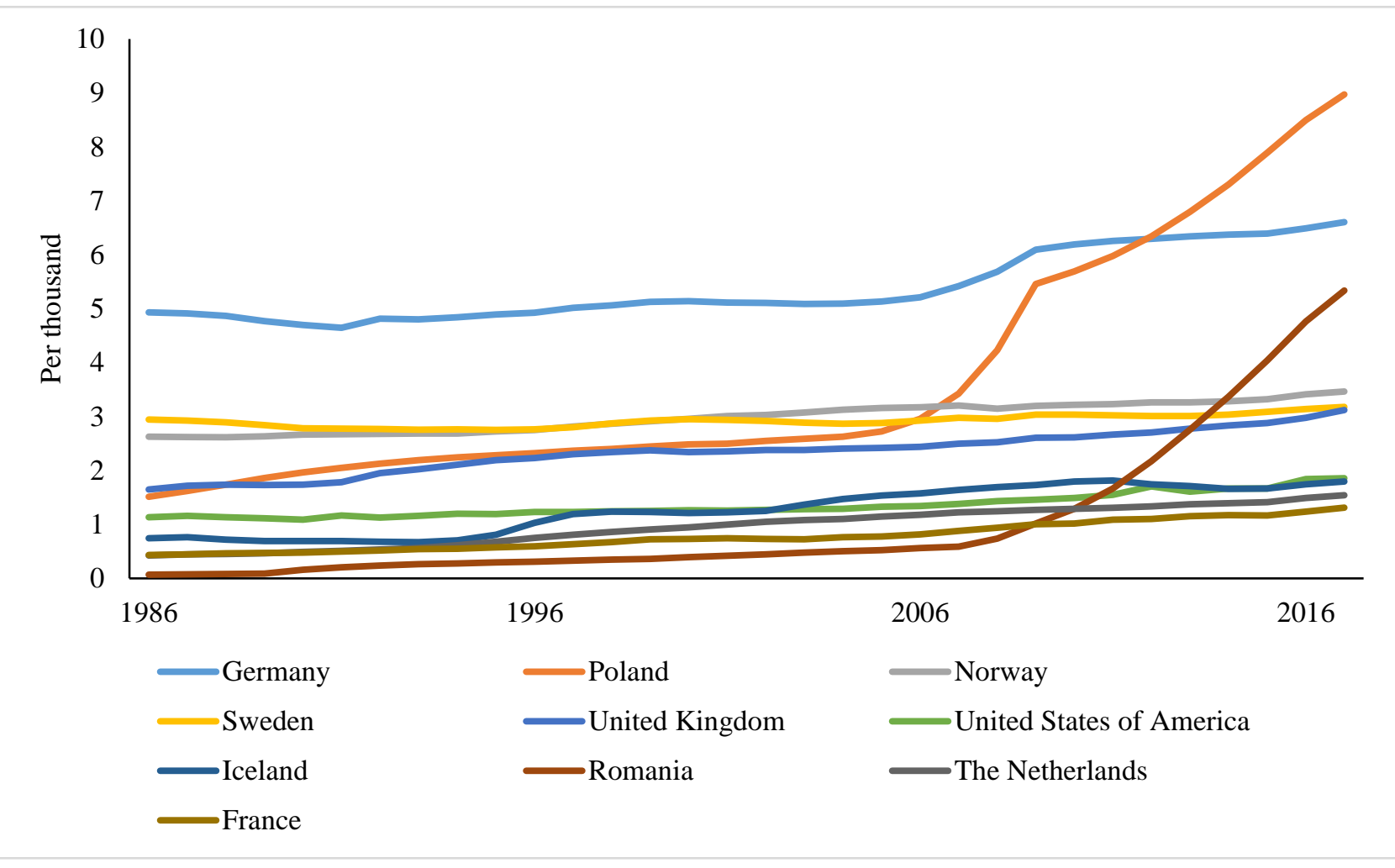


Figure 2. The relative size of the ten largest ethnic groups from the non-Western countries in Denmark

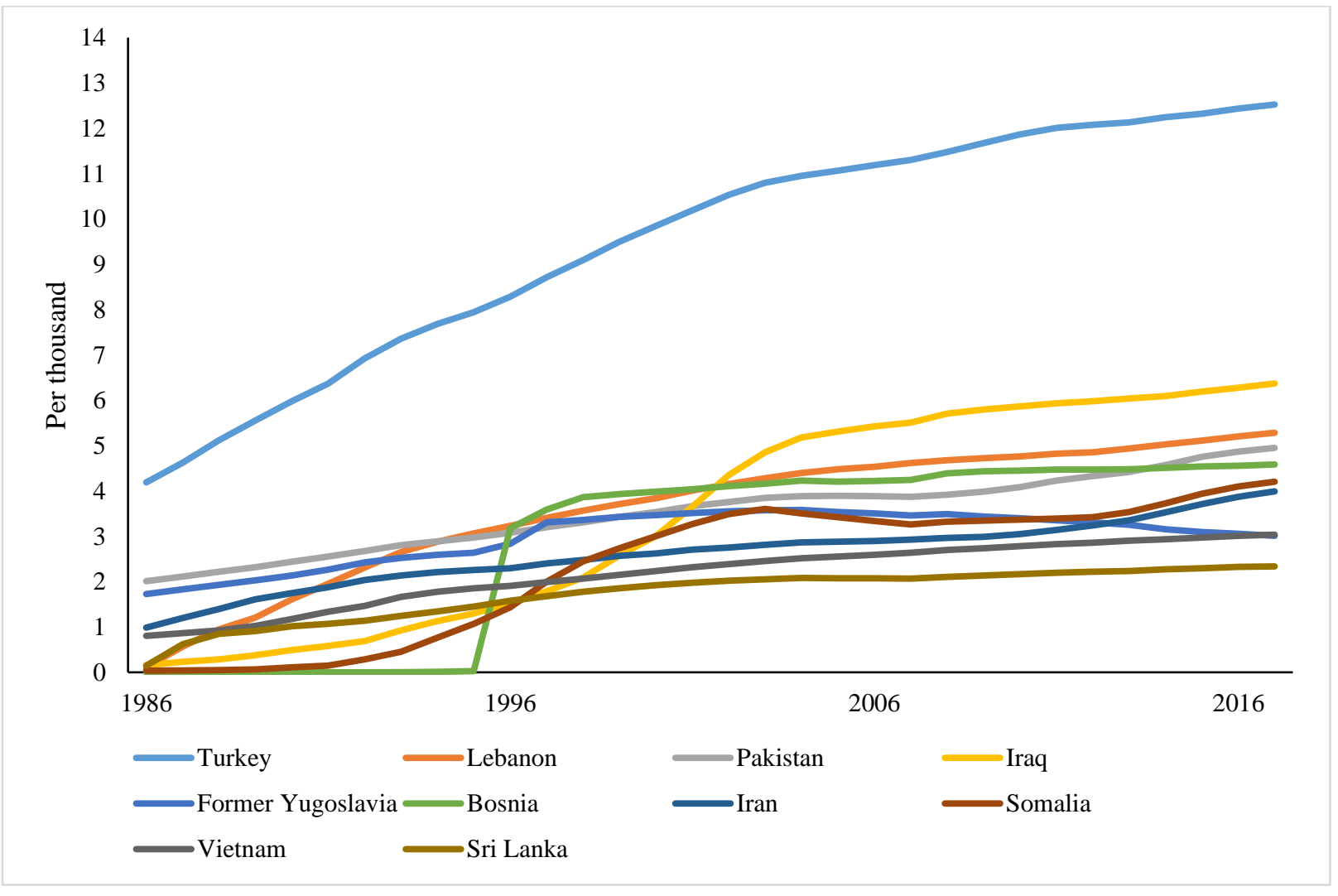


Figure 3. Map of the 11 provinces in Denmark

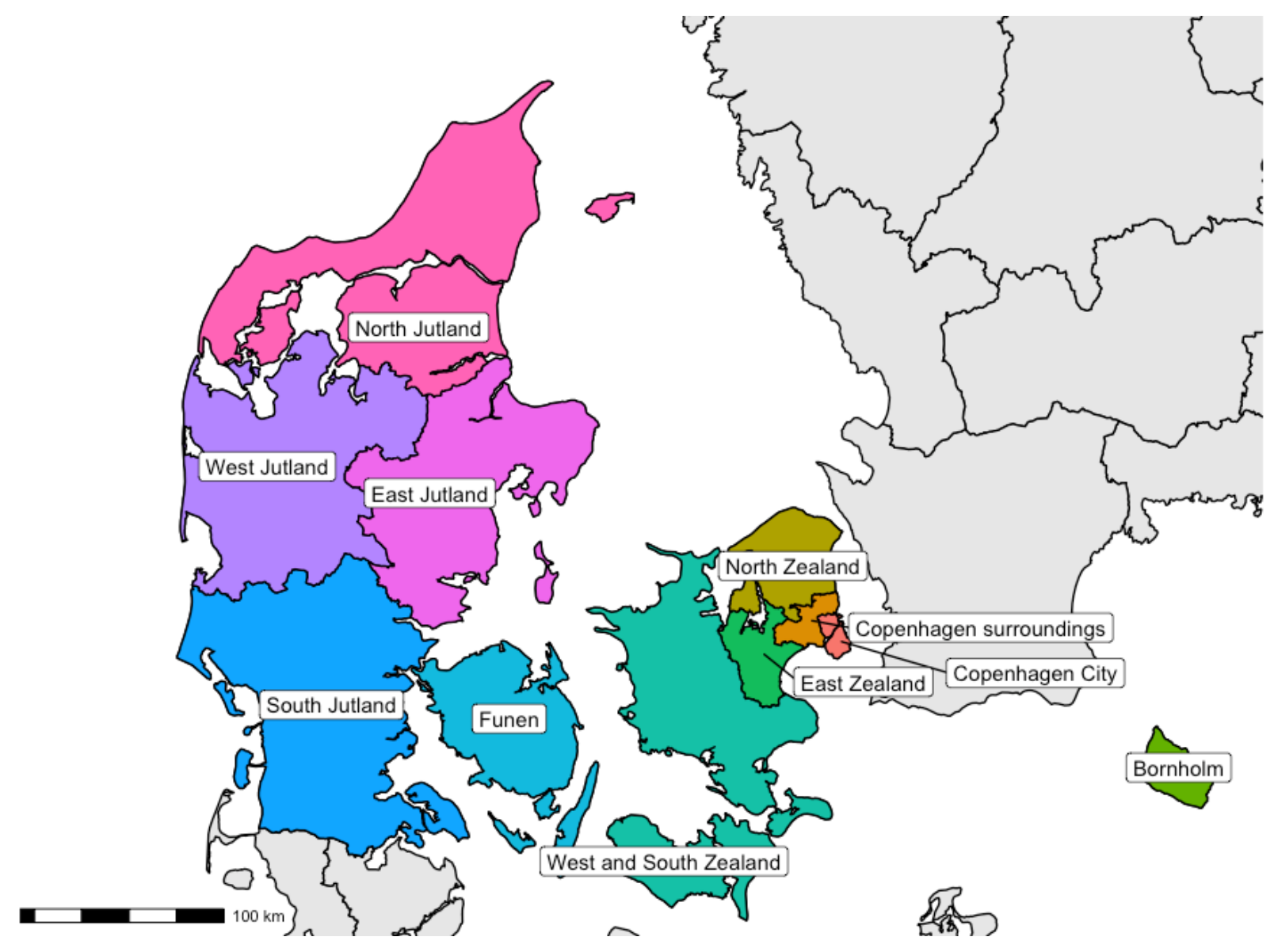


ONLINE SUPPLEMENTARY MATERIALS 
Table A1. Likelihood ratio tests between models in which opportunity structures are measured in local partner markets and province indicator variables and reduced models in which opportunity structures are measured at the national level and province indicator variables are not included

\begin{tabular}{|c|c|c|c|c|c|c|c|c|}
\hline & \multicolumn{4}{|c|}{ Men } & \multicolumn{4}{|c|}{ Women } \\
\hline & $\begin{array}{l}\text { Log } \\
\text { likelihood }\end{array}$ & $\begin{array}{l}\text { Likelihood } \\
\text { Ratio }\end{array}$ & AIC & BIC & $\begin{array}{l}\text { Log } \\
\text { likelihood }\end{array}$ & $\begin{array}{l}\text { Likelihood } \\
\text { ratio }\end{array}$ & AIC & BIC \\
\hline $\begin{array}{l}\text { Mixed union } \\
\text { (native): Local } \\
\text { partner markets }\end{array}$ & -37688.46 & & 75460.92 & 75908.89 & -26729.44 & & 53542.88 & 53975.36 \\
\hline $\begin{array}{l}\text { Mixed union } \\
\text { (native): } \\
\text { National partner } \\
\text { market }\end{array}$ & -37781.91 & $186.89^{*}$ & 75645.81 & 76083.12 & -26930.82 & $402.77^{*}$ & 53943.65 & 54365.83 \\
\hline $\begin{array}{l}\text { Mixed union } \\
\text { (immigrant): } \\
\text { Local partner } \\
\text { markets }\end{array}$ & -18859.97 & & 37803.95 & 38251.92 & -17755.25 & & 35594.51 & 36026.99 \\
\hline $\begin{array}{l}\text { Mixed union } \\
\text { (immigrant): } \\
\text { National partner } \\
\text { market }\end{array}$ & -18885.94 & $51.93^{*}$ & 37853.87 & 38291.18 & -17808.39 & $106.27^{*}$ & 35698.77 & 36120.96 \\
\hline $\begin{array}{l}\text { Unmixed union: } \\
\text { Local partner } \\
\text { markets }\end{array}$ & -47462.57 & & 95009.13 & 95457.1 & -45231.33 & & 90546.66 & 90979.14 \\
\hline $\begin{array}{l}\text { Unmixed union: } \\
\text { National partner } \\
\text { market }\end{array}$ & -47492.08 & $59.03^{*}$ & 95066.16 & 95503.47 & -45361.52 & $260.39 *$ & 90805.05 & 91227.23 \\
\hline
\end{tabular}


Table A2. Discrete-time multilevel event history analyses predicting mixed and unmixed union formation in a competing risks framework (with opportunity structure variables measured at the national level)

\begin{tabular}{|c|c|c|c|c|c|c|}
\hline & \multicolumn{3}{|c|}{ Men } & \multicolumn{3}{|c|}{ Women } \\
\hline & $\begin{array}{c}\text { Mixed } \\
\text { union } \\
\text { (native) }\end{array}$ & $\begin{array}{c}\text { Mixed } \\
\text { union } \\
\text { (immigrant) }\end{array}$ & Unmixed & $\begin{array}{c}\text { Mixed } \\
\text { union } \\
\text { (native) }\end{array}$ & $\begin{array}{c}\text { Mixed union } \\
\text { (immigrant) }\end{array}$ & Unmixed \\
\hline \multicolumn{7}{|l|}{ Individual factors } \\
\hline Time & $\begin{array}{c}1.364^{* * *} \\
(0.014)\end{array}$ & $\begin{array}{l}1.463^{* * *} \\
(0.023)\end{array}$ & $\begin{array}{c}1.484^{* * *} \\
(0.014)\end{array}$ & $\begin{array}{c}1.153^{* * *} \\
(0.013)\end{array}$ & $\begin{array}{l}1.316^{* * * *} \\
(0.021)\end{array}$ & $\begin{array}{l}1.259^{* * *} \\
(0.012)\end{array}$ \\
\hline Time $^{2}$ & $\begin{array}{c}0.984^{* * * *} \\
(0.001)\end{array}$ & $\begin{array}{c}0.985^{* * *} \\
(0.001)\end{array}$ & $\begin{array}{c}0.982^{* * *} \\
(0.000)\end{array}$ & $\begin{array}{c}0.992^{* * * *} \\
(0.001)\end{array}$ & $\begin{array}{c}0.986^{* * * *} \\
(0.001)\end{array}$ & $\begin{array}{c}0.984^{* * *} \\
(0.001)\end{array}$ \\
\hline \multicolumn{7}{|l|}{$\begin{array}{l}\text { Generational status } \\
\text { (ref. = descendant) }\end{array}$} \\
\hline Immigrant: $0-5$ years & $\begin{array}{l}1.096^{*} \\
(0.039)\end{array}$ & $\begin{array}{l}1.159^{*} \\
(0.067)\end{array}$ & $\begin{array}{l}1.082^{*} \\
(0.037)\end{array}$ & $\begin{array}{l}1.122^{* *} \\
(0.046)\end{array}$ & $\begin{array}{c}1.004 \\
(0.058)\end{array}$ & $\begin{array}{l}1.096^{* *} \\
(0.036)\end{array}$ \\
\hline Immigrant: 6-11 years & $\begin{array}{c}1.003 \\
(0.032)\end{array}$ & $\begin{array}{l}1.136^{*} \\
(0.058)\end{array}$ & $\begin{array}{c}1.219^{* * *} \\
(0.036)\end{array}$ & $\begin{array}{l}1.107^{* * *} \\
(0.040)\end{array}$ & $\begin{array}{l}1.179^{* * * *} \\
(0.058)\end{array}$ & $\begin{array}{l}1.276^{* * *} \\
(0.037)\end{array}$ \\
\hline Immigrant: $12-16$ years & $\begin{array}{c}0.678^{* * * *} \\
(0.024)\end{array}$ & $\begin{array}{l}1.179^{* *} \\
(0.061)\end{array}$ & $\begin{array}{l}1.582^{* * * *} \\
(0.047)\end{array}$ & $\begin{array}{c}0.806^{* * * *} \\
(0.031)\end{array}$ & $\begin{array}{l}1.114^{*} \\
(0.057)\end{array}$ & $\begin{array}{l}1.495^{* * *} \\
(0.044)\end{array}$ \\
\hline Immigrant: Age missing & $\begin{array}{c}0.528^{* * *} \\
(0.077)\end{array}$ & $\begin{array}{l}1.172 \\
(0.295)\end{array}$ & $\begin{array}{c}0.775 \\
(0.110)\end{array}$ & $\begin{array}{c}0.397^{* * * *} \\
(0.063)\end{array}$ & $\begin{array}{c}0.619 \\
(0.165)\end{array}$ & $\begin{array}{c}0.437^{* * *} \\
(0.066)\end{array}$ \\
\hline \multicolumn{7}{|l|}{$\begin{array}{l}\text { Educational level } \\
\text { (ref }=\text { no education) }\end{array}$} \\
\hline High-school & $\begin{array}{l}1.188^{* * * *} \\
(0.035)\end{array}$ & $\begin{array}{l}1.079 \\
(0.052)\end{array}$ & $\begin{array}{c}0.846^{* * * *} \\
(0.025)\end{array}$ & $\begin{array}{l}1.421^{* * * *} \\
(0.047)\end{array}$ & $\begin{array}{c}0.917 \\
(0.042)\end{array}$ & $\begin{array}{c}0.761^{* * *} \\
(0.021)\end{array}$ \\
\hline Vocational training & $\begin{array}{l}1.337^{* * *} \\
(0.088)\end{array}$ & $\begin{array}{c}0.927 \\
(0.103)\end{array}$ & $\begin{array}{l}1.995^{* * *} \\
(0.143)\end{array}$ & $\begin{array}{c}1.176 \\
(0.102)\end{array}$ & $\begin{array}{c}0.981 \\
(0.118)\end{array}$ & $\begin{array}{l}1.751^{* * * *} \\
(0.135)\end{array}$ \\
\hline Short-cycle tertiary & $\begin{array}{l}1.187 \\
(0.116)\end{array}$ & $\begin{array}{l}1.214 \\
(0.176)\end{array}$ & $\begin{array}{l}1.659^{* * *} \\
(0.161)\end{array}$ & $\begin{array}{l}1.217 \\
(0.154)\end{array}$ & $\begin{array}{c}0.911 \\
(0.158)\end{array}$ & $\begin{array}{l}1.588^{* * *} \\
(0.168)\end{array}$ \\
\hline Medium-cycle tertiary & $\begin{array}{l}1.351^{* *} \\
(0.142)\end{array}$ & $\begin{array}{l}1.456^{*} \\
(0.226)\end{array}$ & $\begin{array}{c}2.541^{* * *} \\
(0.261)\end{array}$ & $\begin{array}{l}1.424^{* *} \\
(0.173)\end{array}$ & $\begin{array}{c}0.898 \\
(0.156)\end{array}$ & $\begin{array}{c}2.030^{* * *} \\
(0.219)\end{array}$ \\
\hline Long-cycle tertiary & $\begin{array}{l}1.472^{* * *} \\
(0.119)\end{array}$ & $\begin{array}{l}1.248 \\
(0.169)\end{array}$ & $\begin{array}{c}1.814^{* * * *} \\
(0.169)\end{array}$ & $\begin{array}{c}1.490^{* * * *} \\
(0.157)\end{array}$ & $\begin{array}{c}0.885 \\
(0.139)\end{array}$ & $\begin{array}{l}1.256^{*} \\
(0.133)\end{array}$ \\
\hline Education missing & $\begin{array}{c}0.930 \\
(0.047)\end{array}$ & $\begin{array}{l}1.333^{* * * *} \\
(0.086)\end{array}$ & $\begin{array}{l}1.535^{* * * *} \\
(0.052)\end{array}$ & $\begin{array}{c}0.716^{* * * *} \\
(0.046)\end{array}$ & $\begin{array}{c}1.124 \\
(0.076)\end{array}$ & $\begin{array}{c}1.242^{* * *} \\
(0.043)\end{array}$ \\
\hline \multicolumn{7}{|l|}{ Cultural factors } \\
\hline Share of Christians & $\begin{array}{c}1.334^{* * *} \\
(0.083)\end{array}$ & $\begin{array}{c}1.043 \\
(0.085)\end{array}$ & $\begin{array}{c}0.688^{*} \\
(0.121)\end{array}$ & $\begin{array}{c}1.159^{*} \\
(0.083)\end{array}$ & $\begin{array}{c}1.138 \\
(0.096)\end{array}$ & $\begin{array}{c}0.836 \\
(0.128)\end{array}$ \\
\hline Share of Muslims & $\begin{array}{c}0.947 \\
(0.073)\end{array}$ & $\begin{array}{l}1.079 \\
(0.106)\end{array}$ & $\begin{array}{c}1.183 \\
(0.251)\end{array}$ & $\begin{array}{c}0.587^{* * * *} \\
(0.054)\end{array}$ & $\begin{array}{l}1.106 \\
(0.114)\end{array}$ & $\begin{array}{l}1.636^{* *} \\
(0.300)\end{array}$ \\
\hline Scandinavian language & $\begin{array}{c}1.068 \\
(0.043)\end{array}$ & $\begin{array}{c}0.903 \\
(0.050)\end{array}$ & $\begin{array}{c}1.083 \\
(0.141)\end{array}$ & $\begin{array}{c}1.075 \\
(0.053)\end{array}$ & $\begin{array}{c}0.984 \\
(0.054)\end{array}$ & $\begin{array}{c}1.085 \\
(0.118)\end{array}$ \\
\hline Globalization & $\begin{array}{c}1.046 \\
(0.040)\end{array}$ & $\begin{array}{c}0.945 \\
(0.050)\end{array}$ & $\begin{array}{l}0.731^{* * *} \\
(0.087)\end{array}$ & $\begin{array}{c}1.094^{*} \\
(0.049)\end{array}$ & $\begin{array}{c}0.969 \\
(0.051)\end{array}$ & $\begin{array}{c}0.680^{* * * *} \\
(0.069)\end{array}$ \\
\hline \multicolumn{7}{|l|}{ Opportunity structures } \\
\hline Group size & $\begin{array}{c}0.910^{*} \\
(0.040)\end{array}$ & $\begin{array}{c}0.884 \\
(0.066)\end{array}$ & $\begin{array}{c}0.569^{* * * *} \\
(0.022)\end{array}$ & $\begin{array}{c}0.964 \\
(0.055)\end{array}$ & $\begin{array}{c}0.871 \\
(0.066)\end{array}$ & $\begin{array}{l}0.903^{* *} \\
(0.035)\end{array}$ \\
\hline Sex ratio & $\begin{array}{c}1.030 \\
(0.017)\end{array}$ & $\begin{array}{l}1.058^{*} \\
(0.027)\end{array}$ & $\begin{array}{c}0.951^{*} \\
(0.020)\end{array}$ & $\begin{array}{l}0.943^{* *} \\
(0.021)\end{array}$ & $\begin{array}{c}1.019 \\
(0.026)\end{array}$ & $\begin{array}{c}1.027 \\
(0.019)\end{array}$ \\
\hline Educational similarity & 0.983 & $0.902^{*}$ & $1.136^{* * *}$ & $0.919^{*}$ & 0.939 & $1.094^{* *}$ \\
\hline
\end{tabular}




\begin{tabular}{lcccccc} 
& $(0.026)$ & $(0.039)$ & $(0.030)$ & $(0.030)$ & $(0.044)$ & $(0.032)$ \\
\hline Group-level variance & $0.134^{* * *}$ & $0.208^{* * *}$ & $1.335^{* * * *}$ & $0.206^{* * *}$ & $0.229^{* * * *}$ & $0.888^{* * *}$ \\
& $(0.027)$ & $(0.046)$ & $(0.280)$ & $(0.039)$ & $(0.045)$ & $(0.194)$ \\
$\begin{array}{l}\text { Start year indicator } \\
\text { variables }\end{array}$ & YES & YES & YES & YES & YES & YES \\
Observations & & & & & & \\
\hline
\end{tabular}

The table reports odds ratios with standard errors in parentheses. ${ }^{*} p<0.05,{ }^{* *} p<0.01,{ }^{* * *} p<0.001$ (two-tailed tests) 